VATT Working Papers 141

\title{
Household heterogeneity in valuation of heating energy costs
}

Anna Sahari 


\title{
VATT WORKING PAPERS
}

\section{1 \\ Household heterogeneity in valuation of heating energy costs}

\author{
Anna Sahari
}


Anna Sahari, VATT Institute for Economic Research, anna.sahari@vatt.fi

ISBN 978-952-274-274-2 (PDF)

ISSN 1798-0291 (PDF)

URN:ISBN: 978-952-274-274-2

Valtion taloudellinen tutkimuskeskus

VATT Institute for Economic Research

Arkadiankatu 7, 00100 Helsinki, Finland

Helsinki, March 2021 


\title{
Household heterogeneity in valuation of heating energy costs
}

\author{
Anna Sahari \\ VATT Institute for Economic Research \\ anna.sahari@vatt.fi
}

February 19, 2021

\begin{abstract}
This paper studies consumer heterogeneity in the valuation of lifetime heating energy costs. The valuation is expressed as the willingness to pay higher upfront costs to obtain savings over the lifetime of the heating system. The analysis relies on administrative register data on new residential houses built by private persons in Finland during 2010-2011. The data allow estimating the WTP as a function of several observable household characteristics. The median WTP in the estimation sample is $€ 8$, with a range of $€ 2$ to $€ 15$. Households with higher income and education are estimated to have higher WTP. Other characteristics that impact the WTP are household debt, family type and size, current dwelling status and previous experience of building a house.
\end{abstract}

Keywords: Willingness to pay, Energy efficiency, Consumer heterogeneity JEL codes: D12, Q41 


\section{Introduction}

Understanding the different dimensions of individuals' responses to incentives is key in designing efficient policy measures, and in assessing whether such measures are needed to begin with (Allcott et al., 2015, 2014; Chetty et al., 2014). In the context of energy efficiency, accounting for differences among consumers can be crucial in examining the existence and implications of the energy efficiency gap. ${ }^{1}$ These differences include heterogeneity in the pattern and level of energy use, in attention to energy use as well as in the ability and willingness to evaluate the costs of longer term energy consumption.

The goal of this study is to shed light on how households' valuation of lifetime energy costs of a durable good vary with household characteristics. The durable good considered is the main heating system installed into new detached houses in Finland. Analysing new houses has the advantage that existing structures do not limit the choice set. Furthermore, new houses are built by the households themselves acting as developers for their own building project. Therefore, the issue of property developers making suboptimal decisions in terms of the inhabitants of the house is not present in this setting.

The analysis relies on extensive administrative register data on new houses, the house owners and energy prices. These individual-level data allow explicitly incorporating observable consumer heterogeneity into the analysis. The advantage of administrative data is that issues of self-reporting and self-selection are not present, and the sample size is large. According to the results, households' willingness to pay (WTP) higher upfront costs to obtain lower use costs over the lifetime of the heating system varies considerably with household characteristics. The WTP increases with household income and with the education of the house owner, and decreases with family size and the amount of total household debt. Also the current dwelling status of the house owner and previous experience of building a house notably influence the WTP.

This study augments the vast literature dating back to Hausman (1979) and Dubin and McFadden (1984) that analyses consumers' valuation of lifetime energy costs of durable goods. This literature exploits the intertemporal choice situation that consumers face when purchasing energy-using durables: lower energy costs over the lifetime of the good typically require higher costs to be made at the moment of purchase. This tradeoff allows estimating how much consumers are willing to pay now to obtain savings in the future.

Housing and personal transport are interesting sectors to study in this context, because they constitute a large share of consumers' expenditures. Therefore one would expect consumers to be attentive to immediate and long-term energy costs of purchasing and owning a house or a car. Furthermore, the energy use from these sectors contributes to a large share of $\mathrm{CO} 2$ emissions. In the light of increasingly stringent emission reduction targets, it is especially important to understand how consumers value energy costs. This is directly related to the relative effectiveness of price-based policy instruments.

A number of papers have analysed the valuation of fuel economy in passenger vehicles using transaction data from new and used car markets (Busse et al., 2013; Allcott and Wozny, 2014; Sallee et al., 2016; Grigolon et al., 2018). The findings imply some undervaluation of future energy costs, and Allcott and Wozny (2014) interpret this as evidence of consumer myopia, whereas Busse et al. (2013), Sallee et al. (2016) and Grigolon et al. (2018) conclude that consumers are attentive to future fuel costs. A recent study by Gillingham et al. (2021) provides evidence of notable undervaluation and illustrates how

\footnotetext{
${ }^{1}$ The energy efficiency gap, or energy paradox (Allcott and Greenstone, 2012; Jaffe and Stavins, 1994) refers to underinvestment in seemingly profitable energy-saving measures, such as energy-efficient appliances, home improvements or renewable energy technology.
} 
some of the results in previous literature may be biased toward higher valuation due to issues in methodology.

In the context of residential housing, it has been shown that higher energy efficiency labels or energy scores are associated with higher prices (Brounen and Kok, 2011; Walls et al., 2017; Mense, 2018). However, Mense (2018) finds that the price premium does not vary with heating costs, concluding that it is due to a green marketing effect rather than attention to use costs of the dwelling. In contrast, Harjunen and Liski (2014) and Myers (2019) find that fuel costs do capitalize into house prices.

The contradicting conclusions from these studies illustrate the complexity of analysing intertemporal choices that incorporate assumptions on product lifetimes, discount rates, expected energy prices and expected energy use. Another challenge is that individual-level information on consumers is often not available. This means that consumer heterogeneity cannot be explicitly addressed. Yet, all the relevant variables are likely to be viewed differently by different consumers. Lifetimes and expected energy use will depend on usage patterns, especially in the case of cars. Consumers may have different expectations for energy prices. The wide literature on personal discount rates indicates that time preferences vary over individuals. ${ }^{2}$ This is likely to carry over to investment-specific discount rates, which will depend also on individual-specific views of the riskiness of the investment and on possible credit constraints. If common lifetimes and discount rates are assumed, these dimensions of heterogeneity are unaccounted for.

In the context of fuel efficiency, Bento et al. (2012) have shown using simulated data that ignoring consumer heterogeneity in fuel cost valuation will bias the estimates of fuel valuation downwards. Using data on European car markets, Grigolon et al. (2018) illustrate that introducing consumer heterogeneity into a model of vehicle choice changes the results as well as the policy implications. Similar results have been obtained by Newell and Siikamäki (2014 and 2015) in a choice experiment concerning energy efficiency labels and choice of water heaters. They document that individual discount rates, and consequently the WTP for energy efficiency, vary greatly with observable individual characteristics. They emphasize especially the large difference in discount rates associated with the level of education. Newell and Siikamäki (2014) note that assigning a common discount rate for all consumers can result in erroneous inferences on the optimality of households' energyrelated behaviour. Finally, Houde and Myers (2019) document large heterogeneity in consumers' perceptions of energy costs for refrigerators, and show that this heterogeneity can lead to product standards outperforming Pigouvian taxation.

In this study, the data provide some advantages to evaluating valuation of energy costs. First, I can introduce consumer heterogeneity into the analysis by making the WTP a function of observable household characteristics. This is a clear advantage over the studies which must rely at best on aggregate information about consumers. Second, although expected energy consumption cannot be observed, there is likely to be less variance in heating energy consumption across consumers than in passenger vehicle fuel consumption, which indicates potentially less measurement error in this key variable. I base the expected heat consumption measures on a detailed engineering model of unit heat consumption in new detached residential houses, that takes into account regional differences in climate. Finally, the analysis considers houses that rely on electricity as the source of heating energy. A significant share of the electricity cost comes from the local distribution fee of electricity. Distribution fees are regulated and persistent over time, making them a relevant measure of expected prices. Furthermore, because distribution must be bought

\footnotetext{
${ }^{2}$ Frederick et al. (2002) provide an extensive review on the issue. Newell and Siikamäki (2015) discuss time preferences in the context of energy efficiency.
} 
from the local grid operator, I can accurately assign a price to each house based on the location.

This paper is complementary to Sahari (2019), where I use this same data to study how sensitive heating technology choice is to electricity prices. In that paper, I use a different estimation sample and look at results conditional on household characteristics. In contrast, in this paper I focus on the interaction of household characteristics with annual heating costs, which are a function of electricity prices and expected heat consumption. Furthermore, I also take into account the level of upfront costs, in order to be able to express cost sensitivity in terms of a WTP. I discuss the differences in the approach and results in more detail in Section 5.3.

This paper first provides background information on the construction of new residential houses in Finland (Section 2). Section 3 presents the main features of the data. Details are found in appendices A,B and C. In Section 4 I introduce how the WTP is obtained from a model of heating system choice. Section 5 collects the analysis, including estimates of WTP, additional results and robustness checks. Section 6 summarizes and discusses the results.

\section{Background}

Single-family houses are a common dwelling form in Finland: 40 percent of all dwellings are detached houses, and 53 percent of households with more than two members live in detached houses. Between 2010-2019, on average 9400 new detached residential houses were completed annually. These houses are most often built by the households themselves acting as developers for their own building project: in my data, which include years 20002011, 86 percent of houses are owned by private persons at the moment of being built. The second largest owner categories are housing cooperatives ( 7 percent) and private companies (4 percent).

Construction of new homes is strongly regulated by the National Building Code. It contains instructions and mandatory requirements concerning all aspects of building, including minimum requirements for insulation and the functioning of heat, plumbing and ventilation. This sets a common minimum standard for energy efficiency in new buildings. Additionally, as of 2008 all new buildings must have an energy performance certificate and an energy label. Municipal authorities are responsible for enforcing the National Building Code and monitoring the building process.

Due to the Finnish climate, all residential houses are fitted with a main heating system at the moment of building. ${ }^{3}$ Residential heating constitutes 15 percent of total energy consumption in Finland, and households spend on average 4 percent of total expenditures on energy (Statistics Finland, b,a).

When a new house is built, the owner must choose between two main heating technologies: electric heating via cables or radiators, and central heating. A central heating system is based on circulating hot water around the house, and it can accommodate different sources of heat: electricity, ground source heat pumps, wood or oil. ${ }^{4}$ If the house is built within a district heat network, this option is also available. However, the analysis will exclude district heat areas, because many municipalities had in place an obligation for new houses to join the network during the sample period.

\footnotetext{
${ }^{3}$ It is also impossible to meet the Building Code's requirements for indoor temperature and humidity unless a heating system is installed.

${ }^{4}$ Residential use of gas is extremely rare in Finland.
} 
The technology choice is a long-term commitment, as heating technology lifetimes are long and changes to the system are expensive. It is especially costly to change from electric heating to central heating, as this would require fitting the entire house with a water circulation system. However, if the house already has central heating, the source of heat can be changed. For example, old oil heating systems are often replaced by ground source heat pumps.

The most common heating systems in new residential houses are electric heating, central electric heating (referred to as hydroelectric heating) and ground source heat pumps. Of these technologies, ground source heat pumps are most expensive to install, being on average three times as expensive as electric heating. This technology makes use of heat in the ground, and can produce approximately two thirds of the required heating energy from this renewable energy source at zero marginal cost. Electricity is needed to operate the pump and act as back-up energy source.

\section{Data}

The data combine information from administrative registers, engineering models and commercial data providers. The core of the data is an annual 90 percent random sample of all new detached houses built in Finland during 2000-2011, with each building matched to information on its owner and the owners' spouse. These data originate from Statistics Finland. ${ }^{5}$ To construct the cost variables needed for the analysis, the houses are linked to local electricity prices, engineering estimates of heat consumption and to information on the costs of purchasing a heating system. Data on the purchase costs are available for the period 2010-2011, hence the analysis will include houses built during this time. I describe the different variables and data sources in detail below.

\subsection{Houses and house owners}

The information on new houses comes from a form the building owner has to submit when applying for a building permit. The permit identifies the building owner by the personal id number and contains technical details of the house, including the main heating system. The heating system is reported by selecting from a fixed range of options.

The data include only those houses for which the start of building has been documented. ${ }^{6}$ The analysis will include houses owned by a private person, to ensure that the future resident of the house is responsible for making the decisions regarding the heating technology. During 2010-2011, private persons constituted 86 percent of house owners, with the second largest ownership groups being private companies (6 percent) and housing cooperatives (5 percent). Semi-detached houses that consist of two dwellings are excluded from the analysis. This is because the data identify only one owner and one size measure for these houses, and it is not possible to define how costs are shared between the residents of these houses. ${ }^{7}$

Table 1 presents summary statistics on the houses and house owners for the years 2010-2011. Note that individual-specific variables, such as age or education, refer to the building owner, whereas household-specific variables, such as income or debt, are summed from the values of the owner and owner's spouse. Both married and cohabiting couples are included.

\footnotetext{
${ }^{5}$ Statistics Finland does not grant access to full samples of individual-level data.

${ }^{6}$ Builders must inform the authorities once the foundations of the building are in place, to ensure that the building permit does not expire.

${ }^{7}$ For most semi-detached houses the owner type is a housing cooperative.
} 
The summary statistics reveal that most households are families with children, with total annual net income on average $€ 5000$. About half of the households already live in their own house while they are building a new one. On average 8 percent of the individuals in the the 2010-2011 sample are observed building at least one house during the preceding years 2000-2009. Almost all households, 90 percent, are recorded to have debt. This measures the total amount of debt, and it is likely that this mostly consists of mortgage. The average amount of debt scaled by the size of the new house is around $€ 900$ per square meter. Most new houses are located in urban or densely populated areas, as measured by the presence of a town plan at the building site. The average size of new houses is 182 square meters, but this varies notably across the heating technologies.

\subsubsection{Discussion on sample selection}

The data are a representative sample of households who were building a new house during 2010-2011. The external validity of the analysis can be questioned if these households are a very selected group in comparison to the full population. An additional issue is the potential impact of the 2008-2009 financial crisis. It is possible that households who are building immediately post-crisis are a further selected group.

Table 2 presents a comparison of the data and estimation sample to the full adult population as well as all detached house owners. As is to be expected, households who undertake a building project earn more than the population on average. However, the difference is not large, the median pre-tax earned income of house builders is $€ 28200$ whereas the median in the full adult population is $€ 21800$ (values for 2010). The difference is larger for average values, which indicates that new house builder includes some very high earners. ${ }^{8}$ They are also younger and more likely to have young children. The education level is different in the sample and the full population. The share of home builders with at least undergraduate level education increases from 32 to 44 percent during 2005-2010 whereas the share goes from 23 to 26 percent in the full population during the same time period.

The impact of the 2008 crisis is clearly visible in data on construction. Figure 1 plots the number of new detached houses that begun construction and the number of houses that were finished annually over 2000-2019. There is a decreasing trend in the numbers from 2005 onward, and a clear dip in construction in 2009. However, construction rebounded in 2010 and the number of finished houses indicates that projects were not put on hold.

Figure 2 plots mean taxable income by person and the share of people receiving any form of unemployment benefit in the full population and in the data on house builders. The share of unemployment recipients is consistently about 10 percentage points higher in the full population, and this variable follows a similar path in both groups over time. Notably, no change is visible in the development from 2008 onward. ${ }^{9}$ The difference in average income between the groups increases until 2008, when income development stagnates in the house owner group.

These statistics indicate that the house builders were not less impacted by the crisis than the full population, and alleviate concerns that the estimation sample would represent a severely selected part of the population.

\footnotetext{
${ }^{8}$ The conclusions on income remain the same if capital income is included. The data do not include a measure of total wealth or assets, which would most accurately describe the financial situation of the house owners.

${ }^{9}$ Note that this variable is simply the count of individuals who received any unemployment benefit, it is not the official unemployment rate which is defined differently and is a notably lower value.
} 


\section{$3.2 \quad$ Heating system costs}

Total heating costs are composed of the costs of acquiring and installing the heating system and of the annual energy costs over the lifetime of the system. Because the data consist of new houses that are in the process of being built, there can be no observations of these costs and expected values must be constructed for each house. Due to limited data on the fuel costs of oil and wood heating, the focus is on technologies that use electricity as the source of energy. These include electric heating, hydroelectric heating and ground source heat pumps.

\subsubsection{Expected annual heating costs}

Expected annual heating costs are based on engineering estimates of heating energy consumption and on local energy prices. The annual heating cost is defined as $C_{i j}=$ $p_{j}\left(a_{i}\right)\left(\frac{k W h}{m^{2}}\right)$, where $p_{j}$ is the price of energy for technology $j, a_{i}$ is the heated area of house $i$ measured in square meters and $\frac{k W h}{m^{2}}$ is the heat consumption per square meter. I describe the components of heating costs briefly here and in more detail in Appendix B.

Electricity costs are composed of the retail price of electricity and of the distribution fee: $p_{j}=p_{j}^{r}+p_{j}^{d}$. The subscript $j$ refers to distinct prices set for customers with electric heating and hydroelectric heating. Ground source heat pumps are assigned the same price as electric heating, but the price is divided by three, corresponding to the average coefficient of performance of ground source heat pumps during the sample period. Electricity price data originate from the Energy Authority, which maintains a record of all retail contracts offered by retailers in Finland, and acts as the regulatory authority for distribution pricing. Both prices are marginal prices defined in $\mathrm{c} / \mathrm{kWh}$. Block rate contracts are not used in Finland.

To construct expected heating costs, each house is matched to the distribution price and the default retail price prevailing in the local grid area. There were 87 distribution grid areas in Finland during the sample period. The grid areas do not exactly match municipalities, which are the relevant administrative areas. Most distribution grids cover several municipalities, and grid borders can be located within municipalities.

The distribution price can be correctly assigned, because distribution is a service that is always provided by the local grid operator. The distribution prices are matched based on the location of the house defined by the postal code. The retail electricity market in Finland is deregulated, and consumers may contract with any retailer who offers to sell electricity nationwide. However, it is not possible to observe which suppliers the households are contracted with. Therefore, each house is assigned the local default retail price. Alternative ways of defining the retail price are explored in robustness checks.

Expected heat consumption values originate from an engineering model (Sirén and Jokisalo, 2014). This model takes as input the outside temperature and produces a value for heat consumption based on the thermodynamic properties of the building structures. The model has been calibrated to represent an average detached house corresponding to the building regulations in place at a given time. The outdoor temperature is defined as an average at the level of administrative regions, which produces 18 different energy consumption values for houses built in the 18 regions of continental Finland (the island of Aland is excluded from the analysis due to missing data).

The analysis makes use of two sources of exogenous variation in heating costs: the variation in electricity costs due to different distribution price areas and the variation in heat consumption due to different climate conditions across the country. The unit heat need of a new house built according to 2010 building standards varies from $96 \mathrm{kWh}$ per 
square meter to $133 \mathrm{kWh}$, which is a 39 percent difference in heat consumption simply due to geographical location. ${ }^{10}$

Figure 3 displays the variance in heating costs due to electricity price differences across the country. The figure shows the range of heating costs in the estimation sample for an average house consuming $17000 \mathrm{kWh}$ of heating energy annually. The variance in costs is due to differences in distribution prices and default retail prices across the distribution grid areas. The costs range from $€ 1300$ to $€ 2400$. The figure also illustrates that most observations of houses are located around the middle of the total electricity price range.

Electricity distribution prices are regulated, and pricing is based on the costs of operating and maintaining the grid. This results in different price levels across the country, due to differing conditions such as population density and forest coverage. Because these geographical conditions correlate with socio-demographic factors, this creates correlation between price levels and other local factors which may influence heating system demand. To control for local conditions, the analysis will include controls at the level of municipalities. There are over 300 municipalities observed in the data.

\subsubsection{Heating system purchase costs}

Heating system purchase costs include labour and equipment. I construct these costs for each house based a survey of builders in 2010-2011 which includes reported costs of installing heating into new detached residential houses. ${ }^{11}$ Appendix A describes the survey data in detail.

The survey is carried out annually on a random draw of the same population as the register data: households who are in the process of building or have recently completed a new detached house. In 2010 and 2011, the survey asked respondents to state the total approximate costs of their heating system. Out of 3788 survey respondents, 2192 (58 percent) reported the costs. Table 3 displays summary statistics of reported purchase costs by the installed heating system. The sample excludes houses with district heat, to make shares comparable to the register data sample. Note that the category "other" is not reported.

I run an OLS estimation of reported purchase costs on house and household characteristics to produce coefficients that I use to construct purchase costs for the houses in the register data. The costs for electric heating and hydroelectric heating are estimated as a function of area to heat. The cost estimates for ground heat also include heating degree days and and indicators for high income and urban location. The estimation results are reported in Appendix C.

Table 4 presents summary statistics of the constructed costs in the register data by the installed technology. Electric heating has the benefit of small investment costs, but operating costs are high. Moreover, this type of heating does not include the option of switching fuels at a later point in time. Hydroelectric heating in practice has the same operating costs as electric heating, but the purchase cost is higher. Paying a higher upfront cost in this case can be justified by the option value of later on switching to another heat source, such as a heat pump. Ground heat is by far the most expensive heating system in terms of purchase costs. However, the low operating cost makes it the cheapest technology for larger houses in terms of total lifetime costs.

\footnotetext{
${ }^{10}$ The average annual temperature by region ranges from values of 6 degrees Celsius on the south-western coast to around -1 degrees in the north.

${ }^{11}$ Access to the survey data has kindly been supplied by RTS Ltd.
} 


\subsubsection{Discussion on heating costs}

These constructed expected costs will deviate from the expectations that each household has. In defining the expected annual heating costs I assume that the house is built according to the standards required by the National Building Code. It is however possible that the house is better insulated, in which case the heat consumption and resulting annual heating costs are overestimated. For a house with very low heat consumption, the purchase costs of the heating system form a larger share of total costs. The estimation will include building material as a proxy for insulation, as stone houses tend to have better insulation qualities than wood houses.

The main unobservable factor influencing the purchase cost is the type of ground that the house is built on. This impacts the costs of ground heat: drilling the borehole for heat extraction is higher in soft soil such as clay. In these cases using average cost measures will understate the expected costs of ground heat. Soil consistency and distance to bedrock can vary considerably even within very short distances, hence this factor is unlikely to be correlated with observable or unobservable household characteristics.

The unobserved insulation level and soil type both increase the relative importance of the purchase cost compared to the average case. Assuming an average cost structure for these houses will lead to an underestimated willingness to pay. Other unobservable factors that can impact especially the purchase cost include local conditions for heating system supply and labour supply. These can be incorporated into estimation by including location at the detailed level of municipalities. I also include an indicator for town plan areas, which captures factors associated with densely populated areas.

\section{Model and empirical strategy}

In this section I first present the household's choice problem in a general framework and then discuss the empirical strategy and challenges to estimation.

The household must choose a heating system $j$ out of $J$ possible options. These options are limited and the same choice set is available to all households, outside of district heat areas. There is no outside option, because a main heating system must be installed.

Denote by $u_{i j}$ the utility to household $i$ from option $j$. The household will choose option $j$ if $u_{i j}>u_{i m}, \forall j \neq m$. Separating utility into an observable and unobservable part $u_{i j}=v_{i j}+\varepsilon_{i j}$, the choice probability can be expressed as

$$
\operatorname{Pr}\left(u_{i j}>u_{i m}, \forall j \neq m\right)=\operatorname{Pr}\left(\varepsilon_{i m}-\varepsilon_{i j}<v_{i j}-v_{i m}\right)
$$

Assuming that $\varepsilon_{i j}$ are distributed extreme value type I, their difference has a logistic distribution, which implies a standard logit model of discrete choice, where the choice probability has the following form:

$$
P_{i j}=\frac{\left.e^{(} v_{i j}\right)}{\left.\sum_{m} e^{(} v_{i m}\right)}
$$

Define utility for house owner $i$ from heating system $j$ as

$$
v_{i j}=\beta_{i}\left(P C_{i j}+\sum_{t=0}^{T} \delta_{i}^{t} p_{j t} H_{i}\right)+\sum_{k} \alpha_{i k} x_{j k}+\varepsilon_{i j}
$$

where $P C_{i j}$ is purchase cost, $\delta_{i}=1 /\left(1+r_{i}\right)$ is the discount factor, $p_{t j}$ is the expected fuel cost for option $j$ in time $t$ and $H_{i}$ is the expected amount of heating energy consumed 
annually. Other attributes besides price are noted by $x_{j k}$. The variable $\varepsilon_{i j}$ incorporates factors that are not observed in the data.

Assuming that households use the current energy price as their best estimate of future energy prices, the present value heating costs over the lifetime of the system can be expressed as $\sum_{t=0}^{T} \delta_{i}^{t} p_{j} H_{i}=\Delta_{i} C_{i j}$. The multiplier $\Delta_{i}=\sum_{t=0}^{T} \delta_{i}^{t}$ incorporates the discount rate and the lifetime, and transforms the annual heating cost $C_{i j}=p_{j} H_{i}$ into lifetime operating costs. This gives the following utility function:

$$
v_{i j}=\beta_{i}\left(P C_{i j}+\Delta_{i} C_{i j}\right)+\sum_{k} \alpha_{i k} x_{j k}+\varepsilon_{i j}
$$

\subsection{Empirical strategy}

The empirical counterpart of Equation 2 is the following specification:

$$
v_{i j}=\beta P C_{i j}+\gamma C_{i j}+A_{j}+\varepsilon_{i j}
$$

where $P C_{i j}$ is the expected purchase cost and $C_{i j}$ is the expected annual heating cost, comprised of the sum of the retail and distribution price for electricity multiplied by expected heat consumption. $A_{j}$ are alternative-specific constants which stand for technology-specific attributes other than price.

Note that when the heating costs are defined as an annual value, the coefficient on heating costs incorporates the discount rate and lifetime in the form of the discount factor: $\gamma=\beta \Delta_{i}$. Alternatively, the heating costs could be expressed as present value lifetime costs $\Delta C_{i j}$, in which case the coefficient $\gamma$ would be interpreted as an "attention weight" or valuation parameter (see Allcott and Wozny (2014) and Gillingham et al. (2021)). Full valuation of heating costs at the given lifetime and discount rate would be implied by $\beta=\gamma$.

To incorporate household heterogeneity, I define the coefficient on heating costs as a function of observable household characteristics $z_{m i}: \gamma=\bar{\gamma}+\sum_{m} \gamma_{m} z_{m i}$. I prefer to use the observable characteristics instead of random coefficients, because this allows evaluating the sign and magnitude of different characteristics' impact on heating cost valuation. In this case, the equation to estimate is

$$
v_{i j}=\beta P C_{i j}+\left(\gamma+\sum_{m} \gamma_{m} z_{m i}\right) C_{i j}+A_{j}+\varepsilon_{i j}
$$

The object of interest is households' willingness to pay higher upfront costs for a technology to obtain lower use costs over its lifetime. The WTP is defined as the coefficient on annual heating costs divided by the coefficient on purchase cost: $\frac{\gamma}{\beta}=\frac{\beta \Delta}{\beta}$. This measures the change in purchase cost necessary to keep utility constant, given a change in heating costs. In other words, the WTP is the increase in purchase costs households are willing to pay to save $€ 1$ annually over the lifetime of the investment.

It is possible to re-parametrise the model so that the estimated coefficients directly measure WTP (Cameron and James, 1987; Cameron, 1988; Train and Weeks, 2005; Sonnier et al., 2007). Estimation in WTP-space would be preferred if the estimation included random coefficients. Because I do not include random coefficients in the estimation, deriving the WTP from coefficients of the utility function gives identical results to direct estimation of WTP-values. Furthermore, because the set of household characteristics $z_{i}$ includes several indicator variables for household location, estimation in WTP-space runs into convergence difficulties. 
The estimation sample includes houses built during 2010 or 2011 that chose electric heating, hydroelectric heating or ground heat as the main heating system. Due to data limitations, I must drop oil heating, wood heating and the category 'other' from the estimation sample. These categories make up 10 percent of observations during the sample period. By making this restriction, I am assuming that the households in the estimation sample did not include these technologies in their choice set. This assumption is supported by the survey data, in which a clear majority of respondents ( 80 percent of those who installed electric or hydroelectric heating and 70 percent of those with ground heat) stated that they considered at most two alternatives when making the heating system choice.

To capture important unobservable variables that vary by geographical location and type of building site, the estimation includes indicators for municipality and town plan area as interactions with annual heating cost.

Purchase price estimates are not reliable for exceptional house sizes, hence I drop houses with more than 300 square meters of area to heat from the estimation sample. This coincides with the 99th percentile of the house size distribution. The final estimation sample includes 11418 houses.

\section{Analysis}

\subsection{Estimated willingness to pay for heating cost reductions}

Table 5 presents estimation results. Note that all specifications include location type (town plan in force or not) and year indicators. Specifications 2-4 also include 311 municipality indicators. The indicator variables are introduced as interactions with annual heating costs. The values of these coefficients are not reported.

The WTP is calculated for each observation in the sample, based on the full set of coefficients. Hence, in specification 2 which includes no household heterogeneity, the range of the WTP comes from the effect of the municipality indicators. Summary statistics are presented in the lower part of the table. There are some municipalities with very few observations, which results in extreme and very imprecise values of the municipality interaction for these observations. This lead to outliers in the WTP values, hence the summary statistics report the 1st, 50th and 99th percentile of the WTP distribution instead of minimum and maximum values.

The first column shows results from a specification that includes purchase costs and annual heating costs. The ratio of these coefficients implies a WTP of 8 , and this is also the median value in the sample when accounting for variance due to annual and location effects.

The second specification adds municipality interactions. The impact of annual heating costs now varies with location, which leads to WTP values that range between 4 and 14. The third specification introduces further variance due to household characteristics. All interaction effects are statistically significant. In terms of magnitude, the effects are largest for the education level, current dwelling status, previous experience of building and the material of the new house. The WTP in the estimation sample now varies from 2 to 15 , the median value remaining at 8 .

The fourth specification includes a constant for electric heating. This implies that households would compare costs distinctly within the two technology types: electric heating and central heating. ${ }^{12}$ Including the technology fixed effect does not impact the results,

\footnotetext{
${ }^{12}$ Results from the survey indicate that households rarely compare heating systems across the two technology types, see Appendix A
} 
and the estimated effect is not statistically significant.

Figure 4 illustrates how household characteristics impact WTP. For continuous variables the effect is illustrated for a 1 standard deviation increase. Income and total household debt measure the financial situation of the household. These have opposite effects on heating cost valuation. Higher income increases the WTP. The coefficients indicate that a standard deviation increase of about 21000 in annual income increases WTP by 0.49 which is 6 percent of the median value of 8 . In contrast, a standard deviation increase of 560 euros in debt per square meter decreases WTP by 0.27 , which is 3 percent of the median value of WTP. Also higher age and increasing family size decrease the WTP.

The discrete variables have the largest effects on WTP. Undergraduate education increases WTP by 0.57 , and the effect of graduate education is nearly twice as large at 0.90 . Also families with children are estimated to have higher WTP by 0.57 . Together with the impact of family size this indicates that the presence of children causes a discrete increase in the valuation of future costs, but each additional family member brings this value down.

Households who currently reside in an owner-occupied house are estimated to have notably lower WTP than households who live in owner-occupied apartments or in rental housing at the moment of building. Interestingly, the house owners who are observed building a house during 2000-2009 (before the estimation sample period) are estimated to have lower WTP.

The estimated WTP measures the amount of money that households are willing to give up now to obtain savings over the lifetime of the heating system. If a lifetime is assumed, this value can be solved for the implied discount rate. At a lifetime of 15 years, the median WTP of 8 is consistent with an implied discount rate of 11 percent. At the low end of the WTP distribution, the value of 2 implies a discount rate of 70 percent, whereas the high WTP of 14 implies a discount rate of 1 percent. Although heating systems easily last longer than 15 years before needing replacement, minor maintenance needs for central heating technologies arise at around this time. Using a longer lifetime would require assumptions on potential maintenance costs.

\subsection{Robustness checks}

This section summarizes results from robustness checks related to the definition of annual heating costs and heating system purchase costs. Results from these estimations are reported in Table 6 . The columns in the table correspond to the following alternatives:

1. Constant retail electricity price The total electricity price is composed of the distribution fee and retail price. In the analysis, the retail price is defined as the default price prevailing in the local distribution grid. It is however highly possible that the households will not contract with the local default retailer but will buy electricity from one of the several nationwide retailers. To assess the impact of retail price variation, this check defines the retail price for each observation as the lowest retail price that was available nationwide. All cross-sectional variation in prices is then due to differences in distribution prices only, which can be correctly assigned to each observation.

2. Constant annual heat consumption Heating energy consumption varies regionally due to differences in climate across the country. It is possible that households especially in colder parts of the country use additional heat sources such as own firewood to reduce the amount of energy purchased for heating. This check eliminates the regional variance in heat consumption by setting this value at $100 \mathrm{kWh}$ per square meter for all observations. This level corresponds to the heat consumption in southern parts 
of the country. All variance in heating costs is then due to differences in electricity prices only.

3. Alternative definition of purchase costs This robustness check uses an alternative definition for heating system purchase costs. The costs are now based on values reported by The Building Information Foundation. The foundation annually publishes a catalogue detailing the unit costs for all materials and components required in building a detached house, including the heating system. This material is targeted especially at non-professional builders, that is, households who can use the material to draw up a budget for their project. The costs are averages based on prices reported by manufacturers and retailers. The costs for heating systems are divided into costs for material and labour, and the catalogue includes an index for accounting for labour cost differences across the country. The costs for electric heating and hydroelectric heating are reported in euros per square meter, whereas the purchase cost for ground heat is a lump sum of labour and equipment costs.

The robustness checks show that the level of WTP is higher when variance in electricity costs comes from distribution prices only. Also the alternative definition of purchase costs results in a higher WTP on average, although the differences to the base specification are not large. However, across these different specifications, the sign and magnitude of the household characteristics is consistently similar. This indicates that the heterogeneity across households is robustly estimated, even though the level of WTP is sensitive to assumptions on the expected costs.

\subsection{Additional results}

This section presents additional results from estimations on register and survey data. Full results and details are presented in Appendix E.

\subsubsection{Annual heating costs and technology choice}

As an alternative to the WTP estimation, this section presents results from a conditional logit estimation of heating system choice using heating costs only. The specification is otherwise identical to Equation 4, but the purchase cost is dropped from the list of variables. The results therefore mirror the results on WTP but are interpreted differently.

The average marginal effect of heating costs on technology choice is -0.01 , indicating that an increase of $€ 100$ in annual heating costs reduces the choice probability by 1 percent. This effect varies with household characteristics, however not very strongly. As an example, figure 5 plots the average marginal effect of heating cost over the observed range of household income. The sensitivity of heating technology choice to annual heating costs clearly increases with income, but the difference in the effect is not large, going from -0.008 at the lower end of the income distribution to -0.013 at the higher end.

These results are not conditional on the level of heating system purchase costs, and they can therefore be compared to the results obtained in Sahari (2019). In that study, I use the same data to estimate the impact of electricity prices on the choice of heating technology using a multinomial logit framework. The analysis requires no assumptions on heat consumption or purchase costs, and can therefore make full use of the data in terms of including all heating technologies and years 2006-2011 for which electricity price information is available.

In Sahari (2019) I find that the average marginal effect of the distribution price of electricity on the choice of electric heating is around -0.05 for households building during 
2010-2011. This effect did not vary strongly with income. Furthermore, out of the other household characteristics, only current dwelling ownership impacted the sensitivity to the distribution price of electricity. For this characteristic, the impact was opposite to the one found here: sensitivity to the electricity distribution price was stronger for households who currently owned a detached house.

These differences in the sensitivity to electricity price versus total annual heating cost are likely due to these variables measuring different aspects of the choice situation. The impact of electricity prices on technology choice in Sahari (2019) is conditional on house size, household characteristics and detailed indicators for location. It measures purely the attention to electricity price levels. In contrast, the annual heating cost is an interaction of prices, house size and local climate. The annual heating cost is perhaps a more realistic representation of what households presumably are considering when they choose the heating technology. However, because it is an interaction of several variables, it is not possible to extract the effect of individual cost components.

\subsubsection{Estimation on the survey data}

The survey data provide an alternative source of information for estimating WTP, as they allow using self-reported purchase costs for the chosen heating technology. The drawback of these data is the small amount of observations and sample selection; in the survey data estimation sample, ground heat is clearly over-represented. For a detailed comparison of the survey and administrative data, see Appendix A.

The WTP estimated from the survey data is very high; the median value in the estimation sample is estimated to be 53. The survey data do not contain as much information on the households as the register data, but the WTP is found to decrease with family size and be higher for households in the highest income bracket (gross annual earnings above $€ 80$ 000). The impact of household characteristics is therefore similar as in the register data.

The very high level of WTP likely reflects the sample selection and measurement error in the heating system purchase costs. The survey unfortunately did not ask to precisely report different components of costs, but only asked for "total approximate costs of the heating system". Some unrealistically low values are reported, as well as extremely high values which do not seem reasonable. It is possible that survey participants are not defining the purchase cost in the same way. Because the number of observations in the estimation sample is small (1129), the extreme values strongly influence results. ${ }^{13}$

\section{Discussion and conclusions}

This study combines administrative register data on heating system choices in new detached houses with expected heating costs to estimate how house owners value lifetime costs of heating in terms of upfront purchase costs. The strength of the analysis lies in the extensive information on households, which allows exploring how valuation of heating costs varies with household characteristics. The results on household heterogeneity are robust, although the level of the valuation does vary with different ways of defining the main cost variables.

The coefficients from heating technology choice estimation imply that the median willingness to pay is $€ 8$ in upfront costs to receive savings of $€ 1$ annually over the lifetime

\footnotetext{
${ }^{13}$ The estimated WTP remains very high even if the most extreme purchase cost values are dropped from the estimation sample.
} 
of the system. Using a lifetime of 15 years this is consistent with discounting future costs at a rate of 11 percent. This is a low valuation, especially considering that heating technology lifetimes are very long and that the heating system is one of the most important characteristics of a house. However, it is in line with previous research that has found that consumers discount investments into energy-using technology at rates that clearly exceed prevailing financial interest rates. For example, De Groote and Verboven (2019) obtain an average implied discount rate of 15 percent for investments into solar PV technology. Furthermore, studies measuring individuals' time preference have found these values to vary widely across individuals and to be on average higher than financial interest rates (Andersen et al., 2008; Newell and Siikamäki, 2014; Simon et al., 2015).

The results show that household characteristics significantly impact the WTP, and these effects are robust across several robustness checks. The context of this study does not allow identifying what causes these differences across households. I will discuss these results below in light of previous research and present possible mechanisms that drive the results.

The house owners' education strongly affects WTP. Undergraduate level education increases WTP by 0.57 and graduate level education by 0.90 . Higher education has been found to be correlated with environmental awareness, financial literacy and lower personal discount rates (Newell and Siikamäki, 2014; Simon et al., 2015; Ramos et al., 2016; Blasch et al., 2017). These are all factors that could result in a higher valuation of future energy costs in the context of heating technology choice. It is also possible that higher education is correlated with a less risky view of the housing market and its ability to capitalise energy savings into house prices.

Interestingly, families with children are estimated to have higher WTP, the impact of children being comparable to that of graduate level education at 0.57. It is possible that these households view their house as a longer-term investment. This would indicate less concern for the resale value of the house and capitalisation of energy costs, if the household does not plan on selling for many years to come. Although the presence of children increases WTP, each additional family member is found to decrease this value by -0.25 , meaning that larger families have notably lower WTP.

The willingness to pay for future cost reductions increases with income. This is consistent with higher income households having better financial resources to give up money upfront for future savings. Higher income households may also have lower interest rates on loans, again increasing their access to additional financial resources. In contrast, the WTP decreases with the amount of household debt per house size. Households that are relying heavily on debt to finance the new building may be more constrained in their ability to allocate money to the heating system versus other necessary features of the house.

The results also show that the current dwelling status of the house owner has a strong effect on WTP. House owners who live in their own house at the moment of building a new house have lower WTP. The effect is similar in magnitude to the effect of high education, but opposite in sign at -0.95 . It is difficult to interpret this result, especially in light of the results in Sahari (2019) where I find that house ownership increases sensitivity to electricity prices. This implies that in the context of total heating system costs, house ownership incorporates other aspects than purely price sensitivity.

Finally, house owners who are observed building at least once before in the years 20002009 preceding the estimation sample are estimated to have lower WTP by -0.91 . At least two factors may explain this result. First, individuals who have experience of building may be less sensitive to future heating costs if they tend to stick with the technology they are already familiar with. Second, individuals who are observed in the data several times 
may be building with the intent of simply making a profit by selling the house soon after it is finished. Such profit is exempt from capital gains tax, conditional on the owner having lived in the house for at least two years. It is not entirely uncommon for private persons to engage in this activity. In this case the lower WTP would be indicative of an issue of split incentives, where the person making the investment is not minimising total energy use or costs for the final resident of the house.

In terms of policy conclusions, these results reinforce those from previous research, which show that consumer heterogeneity is substantial and stress the need for targeted policy measures to advance energy efficiency investments especially in the housing sector. My results are obtained on a sample which represents households in brand new houses. These households are younger, more highly educated and have slightly higher income than the residents of the existing stock of detached houses. Even in this sample, the level of the valuation of future energy costs is not very high. Given that the results indicate that age, lower income and lower education all decrease the valuation, it is highly likely that the level obtained here is an upper bound for the average valuation level in the existing housing stock. This indicates that energy retrofits, which typically involve high upfront costs and long payback times, could be accelerated with policy measures. My results indicate that income and education are potentially useful indicators in trying to identify those consumers who would mostly benefit from policy interventions.

\section{Acknowledgements}

This paper is based on my Ph.D. dissertation (Aalto University School of Business). I wish to thank Hunt Allcott, Manuel Bagues, Matti Liski, Ralf Martin, Tuomas Pekkarinen and Rauli Svento for comments, as well as seminar participants at the 22nd Annual Conference of the European Association of Environmental and Resource Economists in Zürich, CesIfo Area Conference on Energy and Climate Economics 2016, at the Helsinki Center of Economic Research and at VATT Institute for Economic Research. Funding for this research was provided by the Academy of Finland research program "New Energy" and the Aalto University research project SAGA. Declarations of interest: none.

\section{References}

Allcott, H., Greenstone, M., 2012. Is there an energy efficiency gap? Journal of Economic Perspectives 26, 3-28.

Allcott, H., Knittel, C., Taubinsky, D., 2015. Tagging and targeting of energy efficiency subsidies. American Economic Review 105, 187-91. doi:http://doi.org/10.1257/ aer.p20151008.

Allcott, H., Mullainathan, S., Taubinsky, D., 2014. Energy policy with externalities and internalities. Journal of Public Economics 112, 72-88.

Allcott, H., Wozny, N., 2014. Gasoline prices, fuel economy and the energy paradox. Review of Economics and Statistics 96, 779-795.

Andersen, S., Harrison, G.W., Lau, M.I., Rutström, E.E., 2008. Eliciting risk and time preferences. Econometrica 76, 583-618. URL: http://www.jstor.org/stable/ 40056458. 
Bento, A., Li, S., Roth, K., 2012. Is there an energy paradox in fuel economy? A note on the role of consumer heterogeneity and sorting bias. Economics Letters 115, 44-48.

Blasch, J., Filippini, M., Kumar, N., 2017. Boundedly rational consumers, energy and investment literacy, and the display of information on household appliances. Resource and Energy Economics doi:http://dx.doi.org/10.1016/j.reseneeco.2017.06.001. article in press.

Brounen, D., Kok, N., 2011. On the economics of energy labels in the housing market. Journal of Environmental Economics and Management 62, 166-179.

Busse, M.R., Knittel, C.R., Zettelmeyer, F., 2013. Are consumers myopic? Evidence from new and used car purchases. American Economic Review 103, 220-56. doi:http: //dx.doi.org/10.1257/aer.103.1.220.

Cameron, T.A., 1988. A new paradigm for valuing non-market goods using referendum data: Maximum likelihood estimation by censored logistic regression. Journal of Environmental Economics and Management 15, 355 - 379. URL: http: //www.sciencedirect.com/science/article/pii/0095069688900083, doi:https:// doi.org/10.1016/0095-0696 (88) 90008-3.

Cameron, T.A., James, M.D., 1987. Efficient estimation methods for "closed-ended" contingent valuation surveys. The Review of Economics and Statistics 69, 269-276. URL: http://www.jstor.org/stable/1927234.

Chetty, R., Friedman, J.N., Leth-Petersen, S., Nielsen, T.H., Olsen, T., 2014. Active vs. passive decisions and crowd-out in retirement savings accounts: Evidence from denmark. The Quarterly Journal of Economics 129, 1141-1219. URL: https://doi.org/10. 1093/qje/qju013, doi:10.1093/qje/qju013.

De Groote, O., Verboven, F., 2019. Subsidies and time discounting in new technology adoption: Evidence from solar photovoltaic systems. American Economic Review 109, 2137-72. URL: https://www . aeaweb.org/articles?id=10.1257/aer . 20161343, doi:10.1257/aer. 20161343.

Dubin, J., McFadden, D., 1984. An econometric analysis of residential electric appliance holdings and consumption. Econometrica 52, 345-362.

Frederick, S., Loewenstein, G., O'Donoghue, T., 2002. Time discounting and time preference: A critical review. Journal of Economic Literature 40, 351-401. doi:http: //dx.doi.org/10.1257/002205102320161311.

Gillingham, K., Houde, S., Van Benthem, A., 2021. Consumer myopia in vehicle purchases: Evidence from a natural experiment. American Economic Journal: Economic Policy Forthcoming.

Grigolon, L., Reynaert, M., Verboven, F., 2018. Consumer valuation of fuel costs and tax policy: Evidence from the european car market. American Economic Journal: Economic Policy 10, 193-225. doi:10.1257/pol.20160078.

Harjunen, O., Liski, M., 2014. Not so Myopic Consumers - Evidence on Capitalization of Energy Technologies in a Housing Market. Working paper 4989. CESifo. URL: http://ssrn. com/abstract=2507740. 
Hausman, J., 1979. Individual discount rates and the purchase and utilisation of energyusing durables. The Bell Journal of Economics 10, 33-54.

Houde, S., Myers, E., 2019. Heterogenous (mis)perceptions of energy costs: Implications for measurement and policy design. Working paper WP-25722. NBER.

Jaffe, A.B., Stavins, R.N., 1994. The energy paradox and the diffusion of conservation technology. Resource and Energy Economics 16, 91-122.

Mense, A., 2018. The value of energy efficiency and the role of expected heating costs. Environmental and Resource Economics 71, 671 - 701. doi:https://doi.org/10.1007/ s10640-017-0179-7.

Myers, E., 2019. Are home buyers inattentive? evidence from capitalization of energy costs. American Economic Journal: Economic Policy 11, 165-88. URL: https://www . aeaweb.org/articles?id=10.1257/pol.20170481, doi:10.1257/pol.20170481.

Newell, R., Siikamäki, J., 2014. Nudging energy efficiency behavior: The role of information labels. Journal of The Association of Environmental and Resource Economists 1, $141-160$.

Newell, R.G., Siikamäki, J., 2015. Individual time preferences and energy efficiency. American Economic Review 105, 196-200. doi:http://dx.doi.org/10.1257/aer. p20151010.

Rakennustieto, 2011. Rakennusosien kustannuksia. Rakennustieto Ltd.

Ramos, A., Labandeira, X., Löschel, A., 2016. Pro-environmental households and energy efficiency in spain. Environmental and Resource Economics 63, 367-393. doi:https: //doi.org/10.1007/s10640-015-9899-8.

Sahari, A., 2019. Electricity prices and consumers' long-term technology choices: Evidence from heating investments. European Economic Review 114, 19 - 53. doi:https://doi. org/10.1016/j. euroecorev.2019.02.002.

Sallee, J.M., West, S.E., Fan, W., 2016. Do consumers recognize the value of fuel economy? Evidence from used car prices and gasoline price fluctuations. Journal of Public Economics 135, 61 - 73. doi:https://doi.org/10.1016/j.jpubeco.2016.01.003.

Simon, C.J., Warner, J.T., Pleeter, S., 2015. Discounting, cognition, and financial awareness: New evidence from a change in the military retirement system. Economic Inquiry 53, 318-334. doi:http://dx.doi.org/10.1111/ecin.12146.

Sirén, K., Jokisalo, J., 2014. A two-capacity building thermal model to assess the indoor air temperature dynamics in case of intermittent heating. Technical Report. Aalto University School of Engineering, Department of Civil Engineering. Unpublished manuscript.

Sonnier, G., Ainslie, A., Otter, T., 2007. Heterogeneity distributions of willingness-to-pay in choice models. Quantitative Marketing and Economics 5, 313-331.

Statistics Finland, a. Official statistics of finland: Energy. Available at http://www . tilastokeskus.fi/til/ene_en.html.

Statistics Finland, b. Official statistics of finland: Households' consumption. Available at http://www.stat.fi/til/ktutk/tau_en.html. 
Train, K., Weeks, M., 2005. Discrete choice models in preference space and willingnessto-pay space, in: Applications of simulation methods in environmental and resource economics. Springer Publisher.

Walls, M., Gerarden, T., Palmer, K., Bak, X.F., 2017. Is energy efficiency capitalized into home prices? evidence from three u.s. cities. Journal of Environmental Economics and Management 82, $104-124$. URL: http://www.sciencedirect.com/science/ article/pii/S0095069616304508, doi:https://doi.org/10.1016/j.jeem.2016.11. 006. 


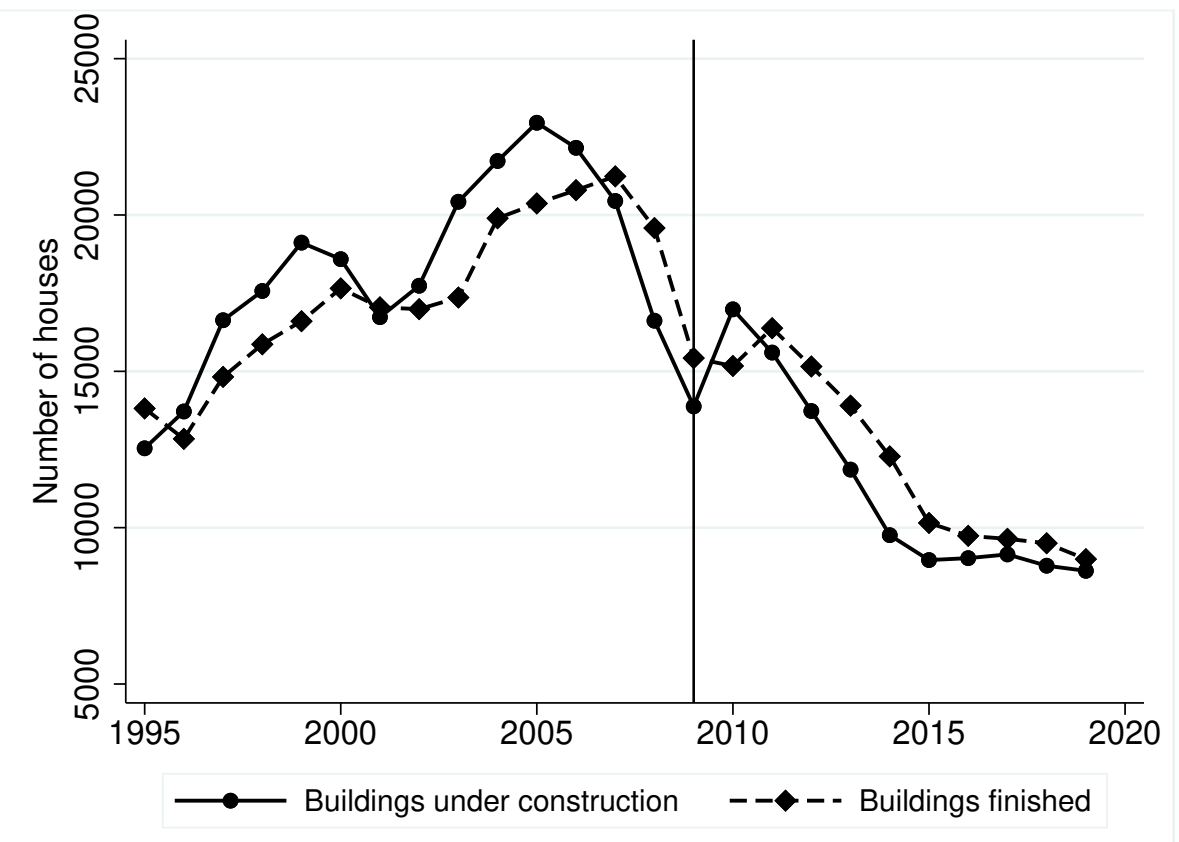

Figure 1: New detached residential houses, started and finished builds.

Notes: The figure depicts the number of started and finished build of new detached residential houses during 2000-2019. The vertical line corresponds to year 2009, to mark the first full year since the financial crisis which began in 2008.

Source: Author's calculations based on official statistics published by Statistics Finland. 


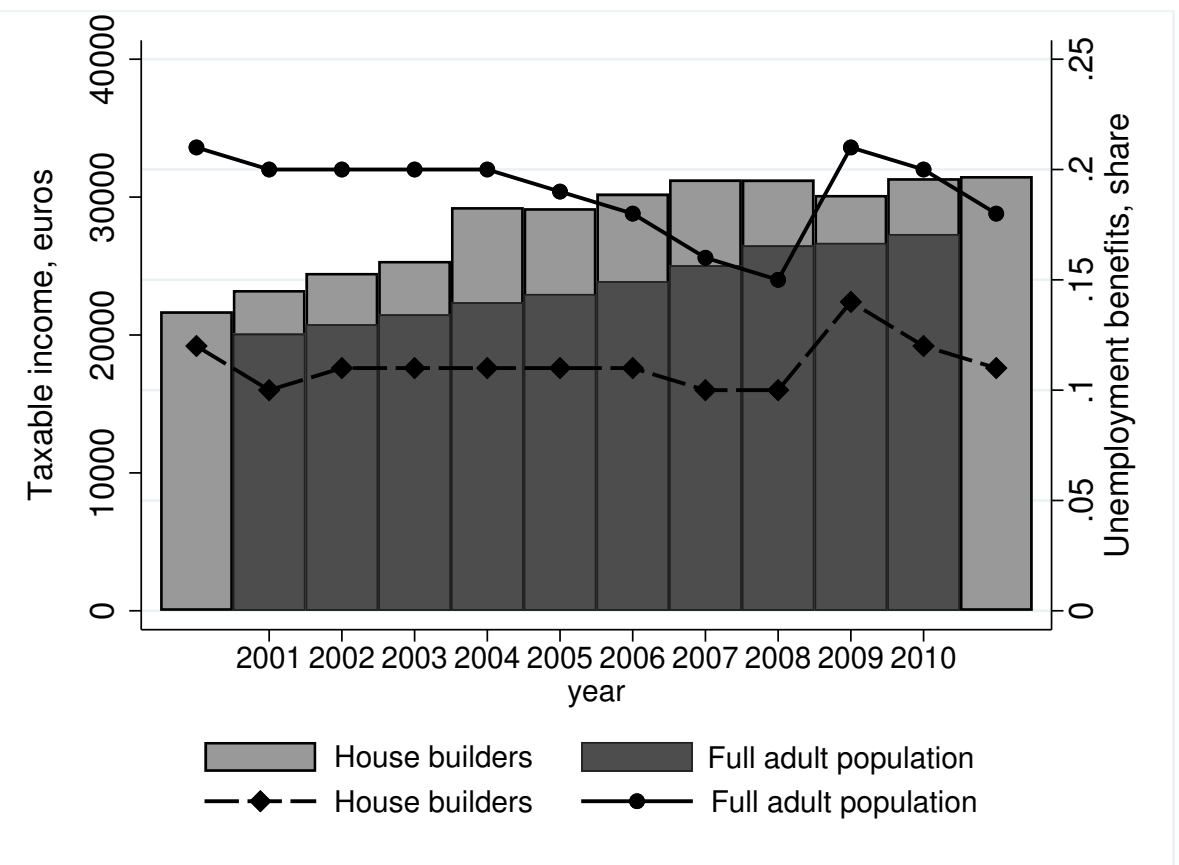

Figure 2: Taxable income and unemployment benefit recipients in new house builders and full adult population .

Notes: The figure illustrates taxable earned income in the data on new house builders (light bars) and in the full adult population (dark bars). The line depicts the share of individuals receiving any form of unemployment benefit in the data on new house builders (dashed line, diamonds) and the full adult population (solid line, circles).

Source: Author's calculations based on official statistics published by The Social Insurance Institution of Finland (KELA) and register data from Statistics Finland. 


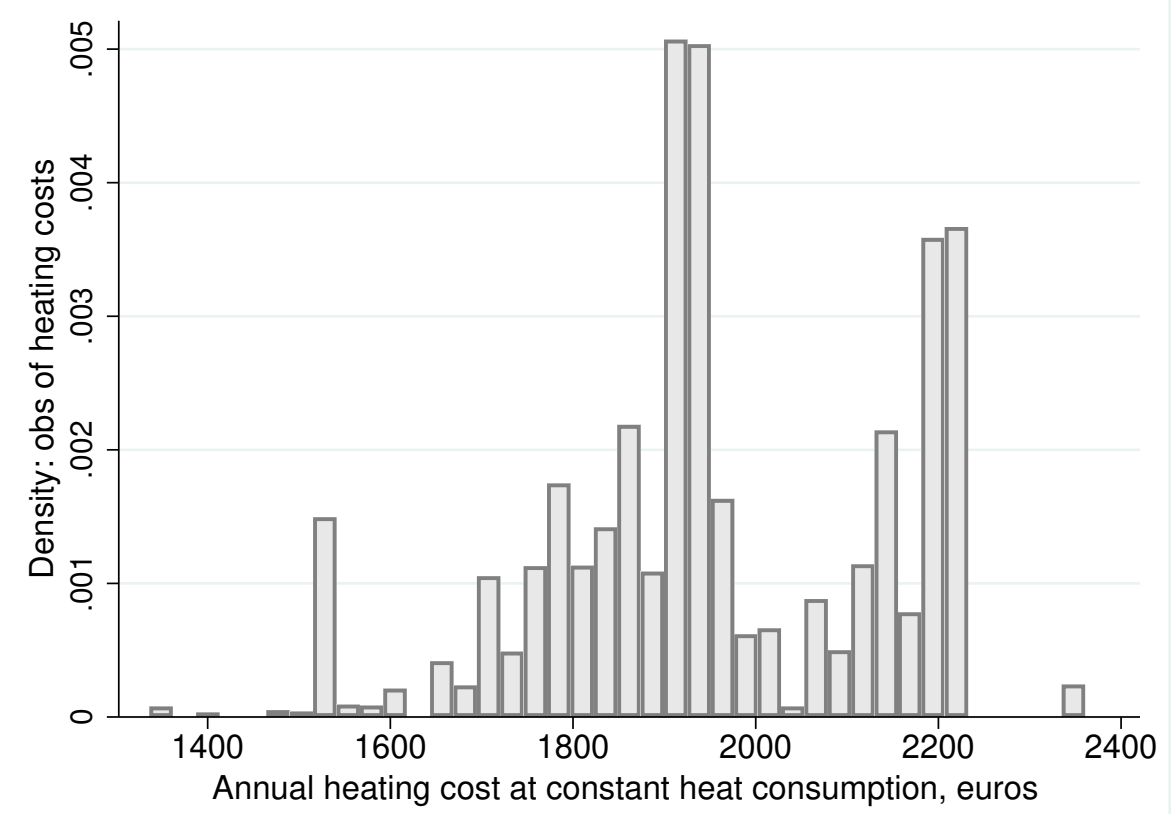

Figure 3: Annual heating costs of an average house for observed range of electricity prices.

Notes: The figure illustrates the impact of electricity price variation on annual heating costs and the density of observations with respect to the electricity price range. All houses in the estimation sample are assigned a common heat consumption of $17000 \mathrm{kWh}$, corresponding to the consumption of an average house. Differences in heating costs then only result from different electricity retail and distribution prices. Source: Author's calculations. 


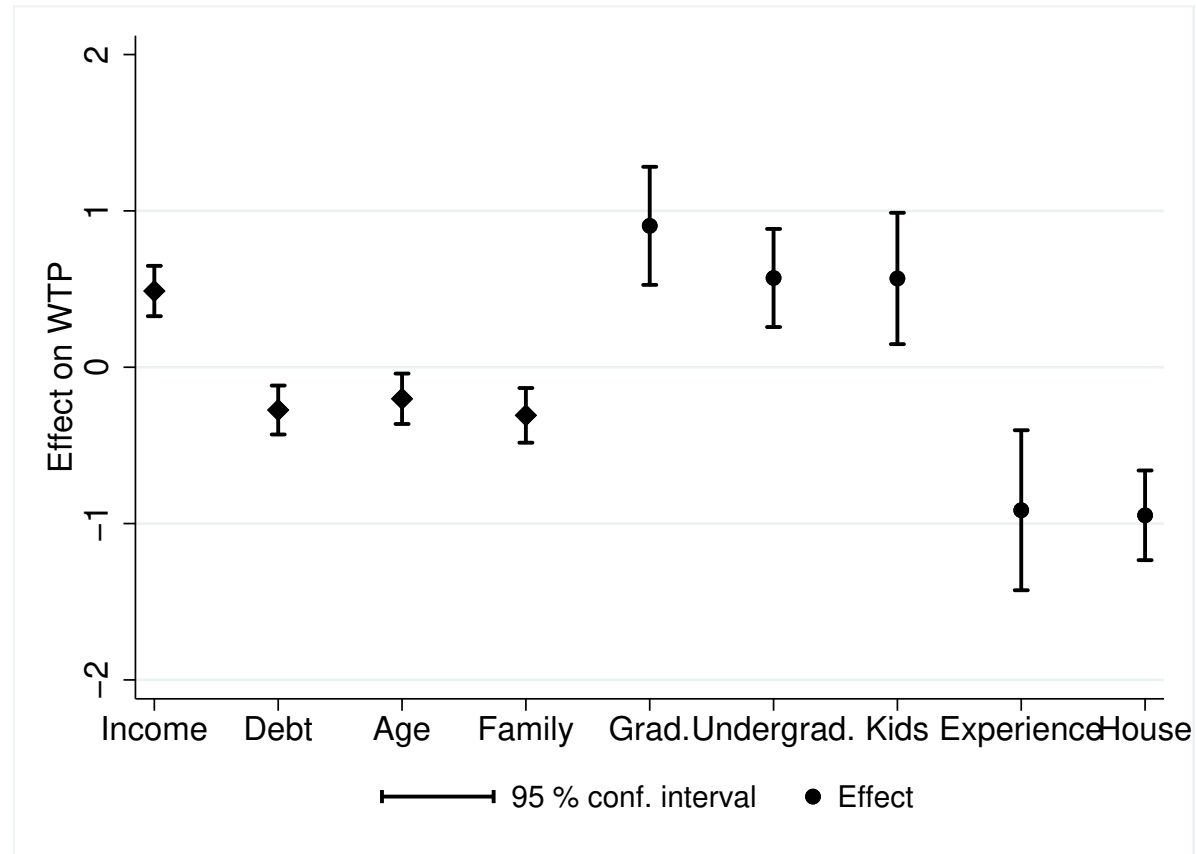

Figure 4: Effect of household characteristics on WTP.

Notes: The figure plots the effect of household characteristics on WTP. Continuous variables depicted with diamonds, the effect is calculated for a standard deviation increase in the variable. These variables include: income (household income net of taxes, sd $€ 21000$ ), debt (household debt scaled by house area, sd $€ 569$, age (sd 10 years), family (household size, sd 1.22). Discrete variables depicted with circles, the effect is calculated for a discrete change. These variables include: grad. (graduate-level education), undergrad. (undergraduate-level education), kids (household with under-aged children), experience (house owner has already built a house during 2000-2009), house (current dwelling is owner-occupied detached house).

Source: Author's calculations. 


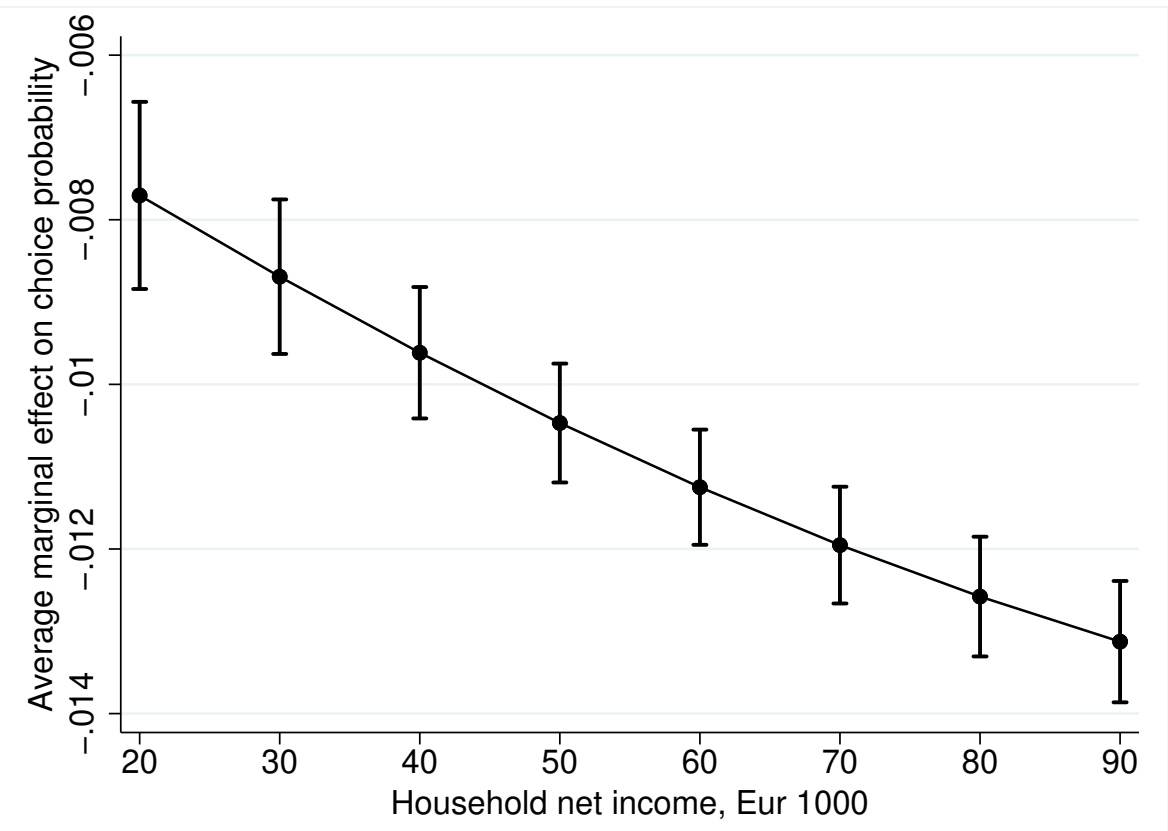

Figure 5: Average marginal effect of heating costs on technology choice by household income.

Notes: The figure plots the average marginal effect of annual heating costs on heating system choice by total household net income. The plotted income range corresponds approximately to the 5th to 95th percentile of the observed income distribution.

Source: Author's calculations. 
Table 1: Summary statistics on new houses and house owners.

\begin{tabular}{lcccccc}
\hline & Electric & Hydroelectric & Ground heat & Wood & Other & Oil \\
\hline House size $\left(\mathrm{m}^{2}\right)$ & 157 & 171 & 210 & 180 & 182 & 194 \\
Town plan area, share & 0.64 & 0.69 & 0.57 & 0.21 & 0.66 & 0.52 \\
& & & & & & \\
Age & 39 & 37 & 37 & 38 & 37 & 42 \\
Education, share & 0.34 & 0.44 & 0.51 & 0.33 & 0.41 & 0.29 \\
Net Income & 45183 & 47425 & 52789 & 41638 & 46470 & 43231 \\
Debt ratio $\left(€ / m^{2}\right)$ & 959 & 978 & 855 & 772 & 939 & 737 \\
Family size & 3.28 & 3.39 & 3.45 & 3.26 & 3.22 & 3.34 \\
Young children, share & 0.37 & 0.44 & 0.46 & 0.35 & 0.41 & 0.38 \\
Current dwelling: own house, share & 0.57 & 0.53 & 0.43 & 0.59 & 0.49 & 0.68 \\
Has built before, share & 0.11 & 0.07 & 0.06 & 0.06 & 0.07 & 0.09 \\
& & & & & & \\
Overall share & 0.35 & 0.18 & 0.37 & 0.05 & 0.04 & 0.01 \\
\hline \hline
\end{tabular}

Notes: The table presents summary statistics of house and household characteristics by installed heating technology for the years 2010-2011. The sample excludes locations with access to the district heat network. The total number of observations is 13 598. 'Town plan' is an indicator for whether a town plan is in force at the building site as opposed to a less detailed master plan. The education variable refers to the share of home owners with education at least at the undergraduate level. Income is defined as all income and benefits net of taxes, in 2010 values. The debt ratio measures total household debt per house size. 'Young children' refers to the share of families with children under 3 years of age. 'Current dwelling' is an indicator which takes value one if the house owner currently lives in an owner-occupied detached house. 'Has built before' is an indicator for if the individual is observed in the data at least once during the preceding years 2000-2009.

Source: Author's calculations based on Statistics Finland register data.

Table 2: Comparison of house builders to whole population

\begin{tabular}{lcccc}
\hline & Data & Estimation sample & Full population & Detached house owners \\
& $2010-2011$ & $2010-2011$ & 2010 & 2010 \\
\hline Income & 28200 & 28400 & 21800 & 23800 \\
Income & 31442 & 31760 & 25325 & 26887 \\
Education & 0.44 & 0.44 & 0.26 & 0.23 \\
Age & 38 & 38 & 49 & 51 \\
Family size & 3.39 & 3.37 & 2.87 & 3.08 \\
Young kids & 0.43 & 0.42 & 0.19 & 0.15 \\
Observations & 16163 & 11418 & 4177174 & 1783719 \\
\hline \hline
\end{tabular}

Notes: The table shows summary statistics on individuals who are in the process of building a new house (data and estimation sample) and on the full adult population in the corresponding year, as well as all detached house owners in the adult population. Income is defined as earned taxable income. Education refers to the share of individuals with at least undergraduate level education. 'Young kids' measures the share of households with children under 3 years of age.

Source: Authors' calculations based on Statistics Finland register data. 
Table 3: Reported heating system costs in survey data.

\begin{tabular}{lccccc}
\hline & Electric & Hydroelectric & Ground heat & Wood & Oil \\
\hline Purchase cost & 4400 & 8500 & 17100 & 12000 & 10500 \\
House size $\left(m^{2}\right)$ & 152 & 165 & 199 & 176 & 192 \\
Cost per $m^{2}$ & 32 & 53 & 90 & 73 & 57 \\
Observations & 254 & 197 & 902 & 152 & 13 \\
Share & 0.21 & 0.14 & 0.42 & 0.08 & 0.01 \\
\hline
\end{tabular}

Notes: The table presents summary statistics of reported heating system purchase costs from a survey of private persons who recently built or were in the process of building a new house for the years 2010-2011. The costs refer to the total purchase costs of the heating system, including labour and equipment. The costs by square meter are calculated as the reported cost divided by the size of the house. Source: Survey data on newly built detached houses, provided by RTS Ltd.

Table 4: Constructed heating system costs in register data.

\begin{tabular}{lccc}
\hline & Electric & Hydroelectric & Ground heat \\
\hline House size $\left(\mathrm{m}^{2}\right)$ & 156 & 171 & 207 \\
Expected heat consumption $(\mathrm{kWh})$ & 16197 & 17410 & 20198 \\
& & & \\
Purchase cost & 5000 & 9227 & 17657 \\
Annual electricity cost & 1077 & 1112 & 452 \\
Annual distribution cost & 772 & 761 & 329 \\
Lifetime cost at $\mathrm{T}=15$ and $\mathrm{r}=5 \%$ & & & \\
& 26040 & 30540 & 27540 \\
\hline \hline
\end{tabular}

Notes: The table shows average constructed heating system costs for installed heating systems in the register data estimation sample. Purchase costs are constructed based on estimates from the survey data. The expected heat consumption is based on an engineering model of heat consumption in new detached houses. The annual electricity cost is the cost of electricity purchased for heating. The annual distribution cost is the distribution fee for electricity.

Source: Author's calculations. 
Table 5: Results: heating system choice estimation

\begin{tabular}{lcccc}
\hline & 1 & 2 & 3 & 4 \\
\hline Purchase cost & -0.224 & -0.284 & -0.240 & -0.268 \\
& $(0.006)$ & $(0.007)$ & $(0.008)$ & $(0.015)$ \\
Annual heating cost & -1.789 & -2.817 & -2.704 & -2.825 \\
& $(0.049)$ & $(0.850)$ & $(1.026)$ & $(1.030)$
\end{tabular}

Interactions with annual heating cost

\begin{tabular}{|c|c|c|c|c|}
\hline Town plan area & $\begin{array}{l}-0.027 \\
(0.031)\end{array}$ & $\begin{array}{c}0.042 \\
(0.037)\end{array}$ & $\begin{array}{c}0.136 \\
(0.043)\end{array}$ & $\begin{array}{c}0.103 \\
(0.046)\end{array}$ \\
\hline Year 2011 & $\begin{array}{l}-0.117 \\
(0.029)\end{array}$ & $\begin{array}{l}-0.057 \\
(0.031)\end{array}$ & $\begin{array}{l}-0.121 \\
(0.036)\end{array}$ & $\begin{array}{l}-0.108 \\
(0.036)\end{array}$ \\
\hline $\begin{array}{l}\text { Household net income } \\
(€ 10000)\end{array}$ & & & $\begin{array}{l}-0.061 \\
(0.009)\end{array}$ & $\begin{array}{l}-0.061 \\
(0.009)\end{array}$ \\
\hline Household debt per area & & & $\begin{array}{c}0.142 \\
(0.036)\end{array}$ & $\begin{array}{c}0.131 \\
(0.036)\end{array}$ \\
\hline $\begin{array}{l}\left(€ 1000 \text { per } m^{2}\right) \\
\text { Age }\end{array}$ & & & $\begin{array}{c}(0.036) \\
0.055 \\
(0.021)\end{array}$ & $\begin{array}{c}(0.036) \\
0.052 \\
(0.021)\end{array}$ \\
\hline Undergraduate education & & & $\begin{array}{l}-0.155 \\
(0.042)\end{array}$ & $\begin{array}{l}-0.153 \\
(0.042)\end{array}$ \\
\hline Graduate education & & & $\begin{array}{l}-0.245 \\
(0.049)\end{array}$ & $\begin{array}{l}-0.242 \\
(0.049)\end{array}$ \\
\hline Family with children & & & $\begin{array}{l}-0.150 \\
(0.057)\end{array}$ & $\begin{array}{l}-0.152 \\
(0.057)\end{array}$ \\
\hline Family size & & & $\begin{array}{c}0.063 \\
(0.020)\end{array}$ & $\begin{array}{c}0.068 \\
(0.020)\end{array}$ \\
\hline House owner & & & $\begin{array}{c}0.253 \\
(0.036)\end{array}$ & $\begin{array}{c}0.253 \\
(0.037)\end{array}$ \\
\hline Has built before & & & $\begin{array}{c}0.243 \\
(0.068)\end{array}$ & $\begin{array}{c}0.245 \\
(0.069)\end{array}$ \\
\hline Material: stone & & & $\begin{array}{l}-0.424 \\
(0.064)\end{array}$ & $\begin{array}{l}-0.417 \\
(0.064)\end{array}$ \\
\hline Constant: electric heating & & & & $\begin{array}{c}-0.130 \\
(0.057)\end{array}$ \\
\hline No. of households & 11418 & 11418 & 8891 & 8891 \\
\hline $11 \_0$ & $-1.25 \mathrm{e}+04$ & $-1.25 \mathrm{e}+04$ & -9767.762 & -9767.762 \\
\hline 11 & $-1.14 \mathrm{e}+04$ & $-1.07 e+04$ & -8203.223 & -8200.638 \\
\hline WTP in estimation sample & & & & \\
\hline Median & 8.11 & 8.42 & 8.47 & 8.10 \\
\hline 1st percentile & 7.98 & 3.65 & 2.16 & 2.40 \\
\hline 99th percentile & 8.63 & 13.95 & 15.46 & 14.43 \\
\hline
\end{tabular}

Notes: The table presents results from a conditional logit estimation of heating system choice. The options are electric heating, hydroelectric heating and ground heat. Indicator variables are: education, undergraduate ( $=1$ if the house owners has undergraduate level education), education, graduate $(=1$ if the house owner has graduate level education), family with children (=1 if a family with children), house owner ( $=1$ if current residence is own house), material: stone ( $=1$ if new house built from stone) and has built before (=1 if house owner is observed building a detached house during 2000-2009). Specifications 2-4 also include 311 municipality indicators interacted with annual heating cost, coefficients not reported. Debt to area measures the amount of total household debt relative to house size. Standard errors in parentheses. Source: Author's calculations. 
Table 6: Robustness checks: heating system choice estimation.

\begin{tabular}{lccc}
\hline & 1 & 2 & 3 \\
\hline Purchase cost & -0.278 & -0.269 & -0.208 \\
& $(0.015)$ & $(0.015)$ & $(0.008)$ \\
Annual heating cost & & & \\
& -3.071 & -3.277 & -3.896 \\
& $(1.075)$ & $(1.191)$ & $(1.036)$
\end{tabular}

Interactions with annual heating cost

\begin{tabular}{lccc} 
Town plan area & 0.106 & 0.101 & 0.430 \\
Year 2011 & $(0.054)$ & $(0.049)$ & $(0.044)$ \\
& -0.092 & -0.111 & -0.275 \\
Household net income & $(0.043)$ & $(0.004)$ & $(0.037)$ \\
(€10 000) & -0.071 & -0.063 & -0.041 \\
Household debt per area & $0.011)$ & $(0.010)$ & $(0.010)$ \\
(€1000 per $\left.m^{2}\right)$ & $(0.043)$ & $(0.038)$ & $(0.038)$ \\
Age & 0.064 & 0.053 & 0.026 \\
& $(0.025)$ & $(0.022)$ & $(0.022)$ \\
Undergraduate education & -0.189 & -0.161 & -0.134 \\
& $(0.049)$ & $(0.044)$ & $(0.044)$ \\
Graduate education & -0.288 & -0.251 & -0.202 \\
Family with children & $(0.058)$ & $(0.052)$ & $(0.051)$ \\
& -0.176 & -0.152 & -0.180 \\
Family size & $(0.067)$ & $(0.061)$ & $(0.060)$ \\
& 0.083 & 0.071 & 0.122 \\
House owner & $(0.023)$ & $(0.021)$ & $(0.021)$ \\
Has built before & 0.294 & 0.272 & 0.263 \\
& $(0.043)$ & $(0.039)$ & $(0.038)$ \\
Material: stone & 0.295 & 0.260 & 0.274 \\
Constant: electric heating & -0.084 & -0.134 & 0.884 \\
& $(0.055)$ & $(0.057)$ & 0.032 \\
\hline No. of households & 8891 & 8891 & 8891 \\
ll & -8174 & -8202 & -8006 \\
\hline Median in estimation sample & & & \\
& $9.62)$ & $(0.072)$ & $(0.071)$ \\
& -0.486 & -0.433 & -0.345 \\
& $(0.077)$ & $(0.067)$ & $(0.067)$ \\
& 16.36 & 14.68 & 21.09 \\
\hline
\end{tabular}

Notes: The table presents results from a conditional logit estimation of heating system choice. The options are electric heating, hydroelectric heating and ground heat. Columns correspond to the following robustness checks: 1) Electricity retail price set at the same level for all observations, 2) Heat consumption set at the same level for all observations, 3) Alternative definition for heating system purchase costs. Indicator variables are: education, undergraduate ( $=1$ if the house owners has undergraduate level education), education, graduate ( $=1$ if the house owner has graduate level education), family with children $(=1$ if a family with children), house owner ( $=1$ if current residence is own house), material: stone ( $=1$ if new house built from stone) and has built before (=1 if house owner is observed building a detached house during 2000-2009). The estimation also includes 311 municipality indicators interacted with annual heating cost, coefficients not reported. Debt to area measures the amount of total household debt relative to house size. Standard errors in parentheses.

Source: Author's calculations. 


\section{Appendix A The survey data}

This appendix describes the survey data which are used to construct estimates of investment costs. The data are provided by RTS Ltd. This company annually surveys households who are in the process of building a new house in order to produce information that it publishes in reports and sells to market actors. The survey respondents are selected randomly, but location is taken into account so that responses are obtained from across the country. The basic structure of the survey remains the same throughout the years, but questions related to specific topics vary.

The survey data are available for the same time period as the full register data: 20002011. Questions related to heating include the installed heating system, the considered heating systems, reasons for choosing the installed system and opinions on different heating technologies. These are included in the survey every year. The cost of the heating system is only included in 2010 and 2011.

Table A.1 shows summary statistics of the survey data. The sample includes years 2000-2011 and all heating systems except district heat. Note that the survey data does not have a category "other" for heating. Instead, the survey explicitly includes exhaust air heat pumps as a main source of heat.

In the survey data, the distribution of house size and location across heating systems is similar to the register data. There seems to be a slightly higher share of town locations in the survey data, however because these are self-reported locations, there may be errors in reporting.

Household characteristics income, age and family size are also similarly distributed in both data. The survey data does not have a measure for education, however it does include the profession of the respondent. The share of clerical employees, entrepreneurs and executives is 59 percent. These professions are likely to indicate at least upper secondary education, which implies that higher education is over-represented in the survey data.

The lower part of Table A.1 presents information on the costs of building. The unit cost of building includes all building costs per house size. These are similar across the heating systems, except for houses that installed wood or oil heating. The lower costs for these houses may be explained by location. The cost of the plot is also notably lower for these categories.

Looking at the shares of heating systems in the survey data reveals that oil heating is over-represented, and the amount of exhaust air heat pumps is also larger than the amount of houses in the heating category "other" in the register data. Correspondingly, the share of ground heat is lower in the full sample of survey data than in the register data.

Table A.2 shows further information on heating choices available in the survey data. The columns indicate the installed technology. In the first panel, the rows show the most common heating technologies and the share of households who had considered these. Only around one third of households who installed electric heating had considered hydroelectric heating or ground heat as an alternative. Only 5 percent considered wood. This implies that the preference for an electric heating system is strong, as a central system is not even considered by most households who install electric heating. Conversely, if the household installs a central heating system, it seems to be more open to considering alternative heat sources; for example half of the households who installed hydroelectric heating also considered ground heat. Overall, the number of alternatives considered is low: a vast majority of households only considered at most two technologies.

The lower panel of Table A.2 shows the stated reasons for the chosen heating system. The importance of costs is evident: 64 percent of households who installed electric heating 
Table A.1: Summary statistics on survey data

\begin{tabular}{lcccccc}
\hline & Electric & Hydroelectric & Ground heat & Wood & Exhaust air & Oil \\
\hline Area $\left(m^{2}\right)$ & 161 & 180 & 209 & 195 & 161 & 208 \\
Town plan area, share & 0.59 & 0.65 & 0.59 & 0.35 & 0.65 & 0.63 \\
& & & & & & \\
Age 30-39, share & 0.38 & 0.44 & 0.47 & 0.41 & 0.40 & 0.45 \\
Gross household income $>80000$ & 0.13 & 0.18 & 0.25 & 0.08 & 0.13 & 0.17 \\
Family size & 3.0 & 3.3 & 3.4 & 3.2 & 3.2 & 3.3 \\
Building cost, $€ / m^{2}$ & 1017 & 1146 & 1234 & 939 & 1205 & 882 \\
Land cost, $€ / m^{2}$ & 22 & 27 & 33 & 11 & 25 & 17 \\
Overall share & 0.39 & 0.12 & 0.25 & 0.10 & 0.10 & 0.05 \\
\hline \hline
\end{tabular}

Notes: The table presents summary statistics of variables in the survey data collected by RTS Ltd. The data include years 2000-2011 and the total number of observations in the presented sample is 29 199. All monetary values in 2010 values.

Source: Annual survey of households in the process of building a detached house, RTS Ltd.

stated low purchase costs as one reason for their choice. Respectively, 77 percent of households who chose ground heat stated low use costs as a basis of their choice. The option to change the source of heat is clearly relevant for hydroelectric heating. Furthermore, environmental aspects play a role in technology choice.

\section{A.1 Comparison of estimations samples in the survey data and register data}

Table A.3 shows summary statistics of both data for the years used in estimation. The samples exclude district heat areas. The samples look very similar except for the distribution of heating technologies. For the estimation sample, the survey data has more ground heat than the register data, and less electric heating. The joint share of electric heating, hydroelectric heating and ground heat is 77 percent in the survey data, while it is 89 percent in the register data. Wood heating and exhaust air heat pumps, which are in the category 'other' in the register data, are over-represented in the survey data. 
Table A.2: Considered options and reasons for heating system choice.

\begin{tabular}{|c|c|c|c|}
\hline & Electric & Hydroelectric & Ground heat \\
\hline \multicolumn{4}{|c|}{ Heating systems considered, share } \\
\hline Electric heating & & 0.23 & 0.13 \\
\hline Hydroelectric heating & 0.27 & & 0.93 \\
\hline Ground heat & 0.32 & 0.50 & \\
\hline Wood heating & 0.05 & 0.10 & 0.14 \\
\hline \multicolumn{4}{|c|}{ Considered at most 2 technologies, share } \\
\hline & 0.90 & 0.79 & 0.85 \\
\hline \multicolumn{4}{|c|}{ Reasons for heating system choice, share } \\
\hline Low investment cost & 0.64 & 0.32 & 0.03 \\
\hline Low use cost & 0.06 & 0.10 & 0.77 \\
\hline Easy maintenance & 0.59 & 0.40 & 0.36 \\
\hline Option to change fuel & 0.01 & 0.42 & 0.09 \\
\hline Ecological & 0.09 & 0.19 & 0.60 \\
\hline
\end{tabular}

Notes: The first panel of the table shows the share of households in each heating category who had considered one or more of the four most common heating technologies as an alternative to their final choice. The second panel displays the share of households who had considered at most two technologies. The third panel lists some of the factors that were stated as the reasons for the installed heating system. The columns refer to the installed heating system.

Source: Annual survey of households in the process of building a detached house, RTS Ltd.

Table A.3: Comparison of summary statistics from survey and register data

\begin{tabular}{lcc}
\hline & Survey data & Register data \\
\hline Gross income $>€ 60$ 000, share & 0.45 & 0.50 \\
Pensioner, share & 0.08 & 0.09 \\
Family size & 3.14 & 3.36 \\
House size $\left(m^{2}\right)$ & 173 & 182 \\
Town plan area, share & 0.61 & 0.60 \\
Metropolitan region, share & 0.19 & 0.20 \\
Electric heating, share & 0.21 & 0.35 \\
Hydroelectric heating, share & 0.14 & 0.18 \\
Ground heat, share & 0.42 & 0.37 \\
Number of households & 4489 & 13598 \\
\hline \hline
\end{tabular}

Notes: The table presents summary statistics from the register data on new detached houses and from an annual survey of households in the process of building a new house. Both samples include years 20102011. The town plan area refers to the share of houses built on a site where a town plan is in force. The metropolitan region measures the share of houses built in the region where the capital city is located. Source: Survey data (RTS Ltd.) and administrative register data (Statistics Finland). 


\section{Appendix B Electricity prices}

To form the expected annual heating cost for each house, the energy price must be multiplied by the amount of energy consumed for heating. The energy price for technology $j$ is the sum of the electricity retail price $p_{j}^{r}$ and the distribution fee $p_{j}^{d}$. For ground heat, the electricity costs are divided by three, which is the expected coefficient of performance for ground heat pumps. ${ }^{14}$

During the sample period, both prices included a fixed fee and a marginal cost in $\mathrm{c} / \mathrm{kWh}$. In the data provided by the Energy Authority, the fixed fee has been averaged over the expected annual load to produce prices that are defined in c/kWh only. The expected load is constant within a customer category and across all distributors and retailers. The categories relevant for this study are customers with electric heating (expected load 18 $000 \mathrm{kWh}$ ) and customers with hydroelectric heating (expected load $20000 \mathrm{kWh}$ ).

The distribution of electricity is provided by local grid operators, who are responsible for maintaining the grid and metering consumption. There were 87 distribution grid operators in 2010 and 85 in $2011 .^{15}$ Distribution pricing is heavily regulated. Prices are based on the costs of operating the grid, and distributors are allowed to earn a reasonable return on investment. Factors such as population density, forest coverage, snow conditions and the length of the grid influence the price level. These factors vary across the country, resulting in distribution price differences. ${ }^{16}$

The retail market is deregulated, and customers may contract with any of several electricity suppliers who operate on the market. It is not possible to know which supplier the households buy their electricity from. Therefore, each observation in the data is assigned the default retail price in the corresponding grid area. There were 66 retailers who acted as default suppliers for a given distribution grid. The default supplier is defined as the supplier with a dominant market position within the grid. Typically this is the local electricity company, which used to be the incumbent supplier before the market was deregulated.

Table B.1 presents summary statistics on electricity prices. Overall, the pricing for the two groups is very similar. Prices for electric heating are on average 10 percent higher than prices for hydroelectric heating, but in terms of the range of prices available and the development over time, the prices do not differ. The distribution prices for both groups increase by over 20 percent from 2010 to 2011. This price increase is due to a large increase in the electricity tax faced by consumers.

\footnotetext{
${ }^{14}$ This value is selected based on personal communication with Juha Jokisalo from Aalto University Department of Energy Technology and Jussi Hirvonen from the Finnish Heat Pump Association. The coefficient of performance used in the National Building Code during this time was 2.5. However, according to experts this value had been set as a lower bound, in order to be sure not to overestimate the benefits of ground heat. Actual, observed values were typically around 3.

${ }^{15}$ The value decreases because of small grids merging with a neighbouring network.

${ }^{16}$ The correlations between grid characteristics and distribution price levels are explored in detail in Sahari (2019)
} 
Table B.1: Summary statistics on electricity prices.

\begin{tabular}{ccccc|ccccc}
\hline \multicolumn{4}{c}{ Distribution prices } & \multicolumn{3}{c}{ Retail prices } \\
\hline & \multicolumn{1}{c}{ Electric } & \multicolumn{2}{c}{ Hydroelectric } & \multicolumn{3}{c}{ Hydroelectric } \\
& Mean & Sd & Mean & Sd & Mean & Sd & Mean & Sd \\
2010 & 4.41 & 0.50 & 3.96 & 0.44 & 6.42 & 0.54 & 6.13 & 0.59 \\
2011 & 5.36 & 0.52 & 4.90 & 0.45 & 6.99 & 0.66 & 6.70 & 0.70 \\
\hline \hline
\end{tabular}

Notes: The table presents summary statistics on electricity prices in the estimation sample. The prices are presented for two customer groups: those with electric heating and those with hydroelectric heating. Source: Author's calculations based on price data published by the Energy Authority. 


\section{Appendix C Heating system purchase costs}

I use information from reported purchase costs in the survey data to construct heating system purchase costs for houses in the register data. A standard OLS regression relates observable house and household characteristics to the reported costs, and I use the coefficients to construct costs for observations in the register data.

Table C.1 reports estimation results. For all systems, costs are a linear function of area to heat. Introducing a cubic term would increase the fit, but results in negative values as house size increases. Costs for electric heating and ground heat are correlated with household and location characteristics. Gross household income above 80000 indicates higher purchase costs. This may reflect quality, or be related to high income households building in locations where costs are higher. This is typically the case in town locations, and indeed the unit purchase costs of ground heat are higher if a town plan prevails on the building site. Furthermore, the costs of ground heat are a decreasing function of heating degree days. In expectation, the purchase costs should increase with colder climate, because the increased heat need means that a deeper hole must be drilled for heat extraction. However, higher values for heating degree days are observed in eastern and northern parts of the country, which tend to have a lower overall cost level. This effect thus seems to dominate the effect of increased heat need.

The figures below plot the reported costs in the survey data and the cost estimates for each heating option. Common features for all the options are that there is a large variance in the reported costs and that the observations are concentrated around even sums. For example, for hydroelectric heating there is notable concentration around 10000 and for ground heat at values of 15000 and 20000 . This is probably due to the formulation of the survey question: it asked to state heating system costs as 'total approximate costs'.

Figure C.1 shows costs for electric heating. Most reported costs lie well below 10 000 euros, but there are two outliers at unrealistically high values of 30000 . The estimated costs capture the average cost level reasonably well, but are estimated on very few observations towards the higher end of the house size distribution.

Figure C.2 shows the costs for hydroelectric heating. Again, the estimated costs match the reported average well, but the large variance in the reported costs cannot be captured by the estimation.

Finally, Figure C.3 plots the data and the estimates for ground heat. The reported costs show some unrealistically low values close to zero costs. The heat pump and the drilling of the borehole both cost around 5000 Euros, hence it is not possible that investment costs would be much lower than 10000 euros. For this reason, costs below 8000 were not included in estimation in order not to make the level of estimated costs too low. 


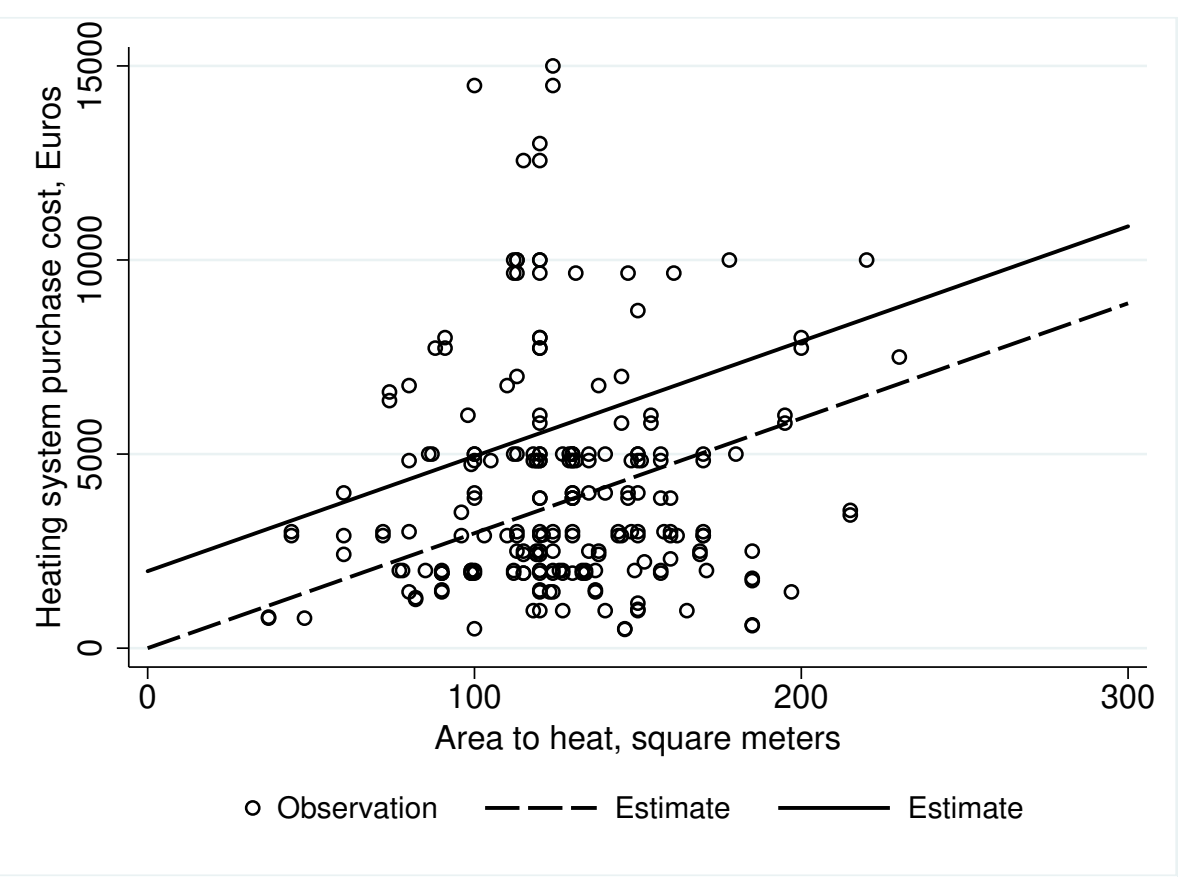

Figure C.1: Reported and estimated costs for electric heating.

Notes: The figure displays the reported costs for electric heating in the survey data, as well as the cost estimates based on coefficients reported in Table C.1. The solid line presents costs for households with gross annual income above 80000 euros.

Source: Survey data provided by RTS Ltd. and author's calculations.

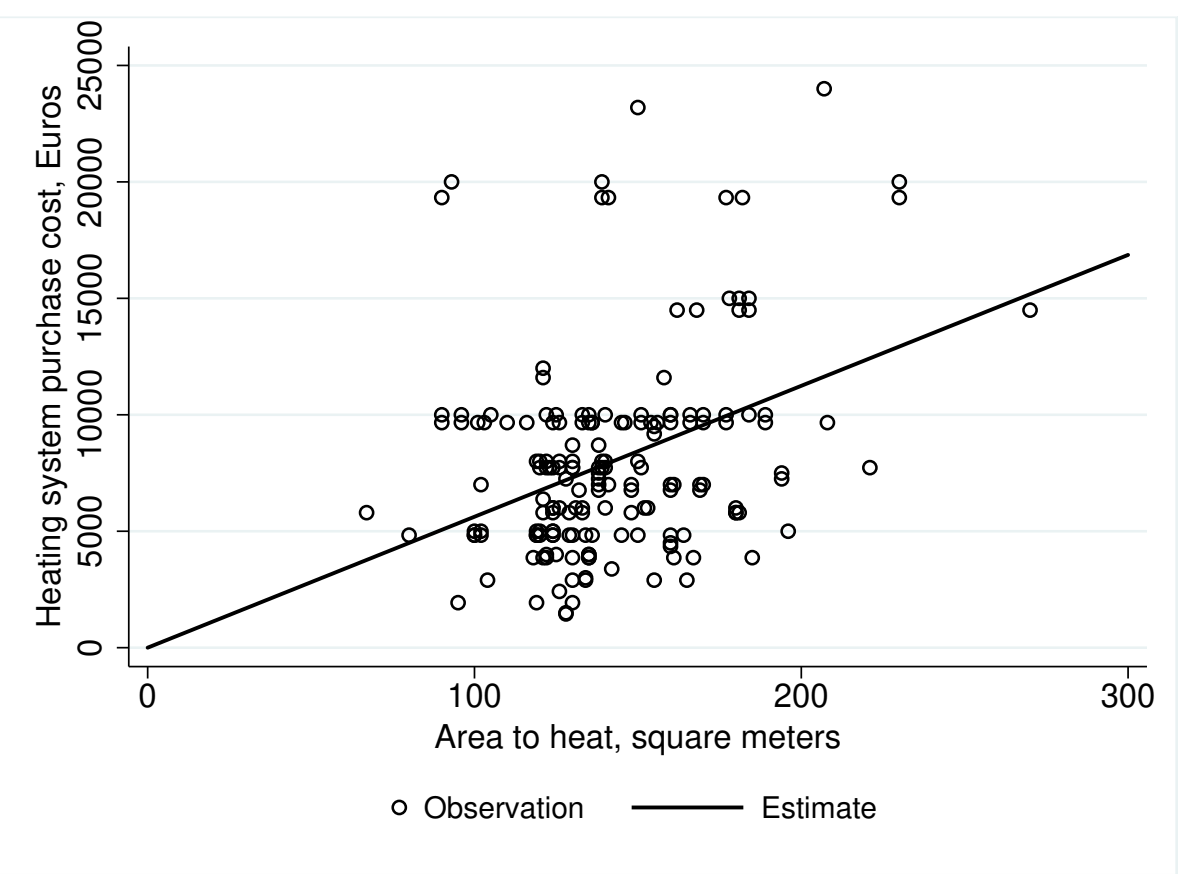

Figure C.2: Reported and estimated costs for hydroelectric heating.

Notes: The figure displays the reported costs for hydroelectric heating in the survey data, as well as the cost estimates based on coefficients reported in Table C.1.

Source: Survey data provided by RTS Ltd. and author's calculations. 


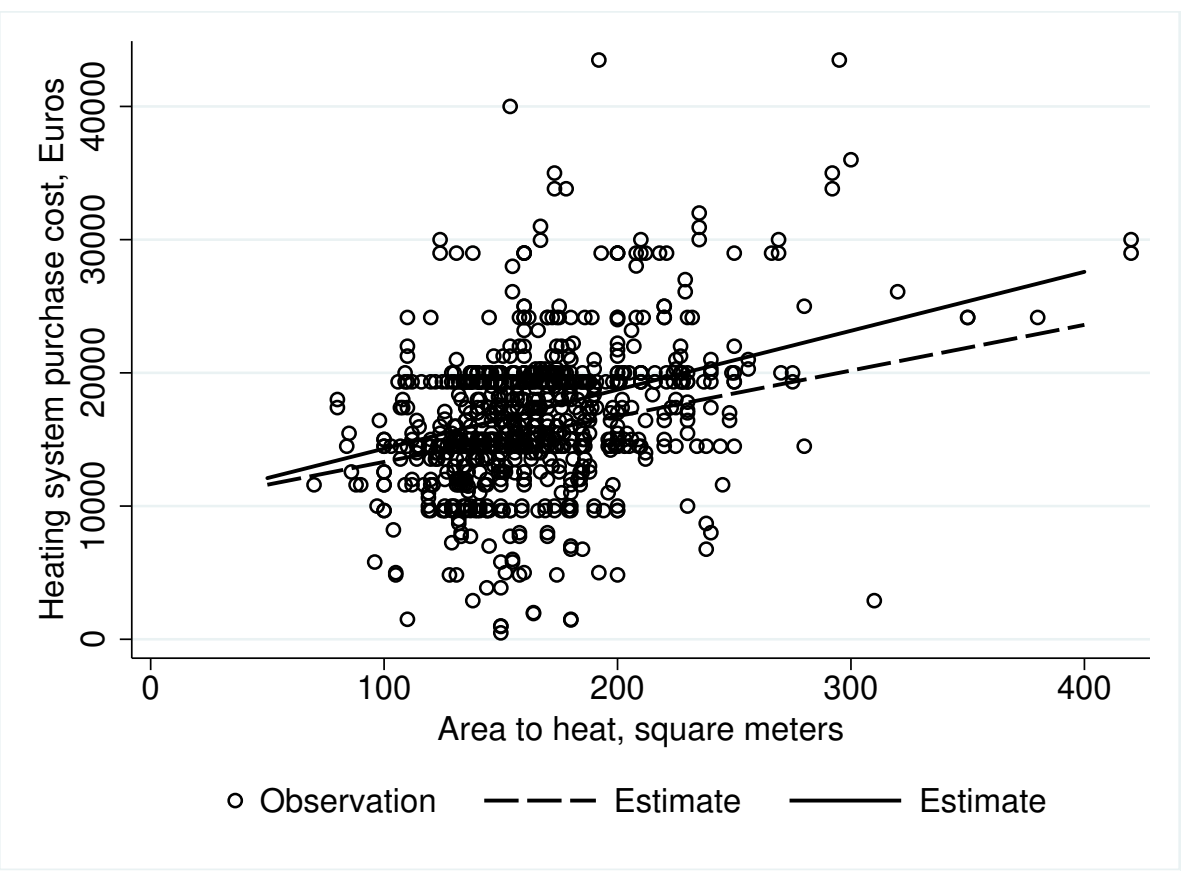

Figure C.3: Reported and estimated costs for ground heat.

Notes: The figure displays the reported costs for ground heat in the survey data, as well as the cost estimates based coefficients reported in Table C.1. The estimates are calculated using at the average value of heating degree days. The solid line refers to locations where a town plan is in force.

Source: Survey data provided by RTS Ltd. and author's calculations.

Table C.1: Estimates of heating system purchase costs

\begin{tabular}{lccc}
\hline & Electric & Hydroelectric & Ground heat \\
\hline Area to heat & $29.614^{* * *}$ & $56.217^{* * *}$ & $33.895^{* * *}$ \\
& $(1.573)$ & $(2.199)$ & $(4.010)$ \\
High income & $1982.809^{*}$ & & $1334.834^{* * *}$ \\
& $(1171.762)$ & & $(358.986)$ \\
Heating degree days & & $-1.132^{* * *}$ \\
& & & $(0.335)$ \\
Interaction effects with house size & & $9.950^{* * *}$ \\
Location: town & & & $(1.872)$ \\
& & & $15171.71^{* * *}$ \\
Constant & & & $(1793.033)$ \\
& & 174 & 755 \\
Observations & 216 & 0.80 & 0.25 \\
$R^{2}$ & 0.61 & & \\
\hline \hline
\end{tabular}

Notes: The table presents results from an OLS regression of reported heating system purchase costs on house and household characteristics. Significance levels: * $10 \%, * * 5 \%, * * * 1 \%$.

Source: Author's calculations. 


\section{Appendix D Robustness checks}

Estimating the WTP requires assumptions on the level of annual heating costs and on the purchase cost of heating systems. The robustness checks examine how results are affected by alternative ways of defining these variables and the estimation sample.

The first robustness check sets the retail price of electricity for all households at the lowest price available nationwide. Assuming that all consumers buy electricity at the lowest price available eliminates retail price variation from the annual heating cost. Differences in the total electricity price now originate from distribution prices only.

The second robustness check assumes that heat consumption is uniform across all locations at $100 \mathrm{kWh}$ per square meter. This corresponds to the consumption in the southern parts of the country and implies that houses located in colder regions would either insulate more or use additional heat sources such as fireplaces to compensate for the local climate. Variation in heating costs is now only due to electricity price differences.

The third robustness check uses an alternative definition of purchase costs. The Building Information Foundation annually publishes a catalogue of unit prices for all materials and labour that are required for building a new house, including the heating system (Rakennustieto, 2011). The catalogue is intended to serve as a guide and source of information for consumers. The foundation annually collects unit prices of materials and equipment from manufacturers and importers and publishes average price levels in the catalogue. The price information also includes an index for adjusting labour costs regionally.

Table D.1 reports summary statistics on the alternative definitions of purchase costs for the chosen technologies in the estimation sample. The costs based on estimates from the survey data produce a wider range of values because these are a function of more than one variable. The averages are similar except for hydroelectric heating. For this technology, the costs reported in the catalogue are much lower than the cost level reported in the survey.

Figure D.1 illustrates how the distribution of annual heating costs changes with different assumptions on electricity prices and heat consumption. Removing the retail price variation or the heat consumption variation from the definition of costs causes the annual heating costs to be somewhat lower overall, and naturally the spread of the costs is slightly reduced.

The results from the robustness checks are presented in Table 6 in the main text. 


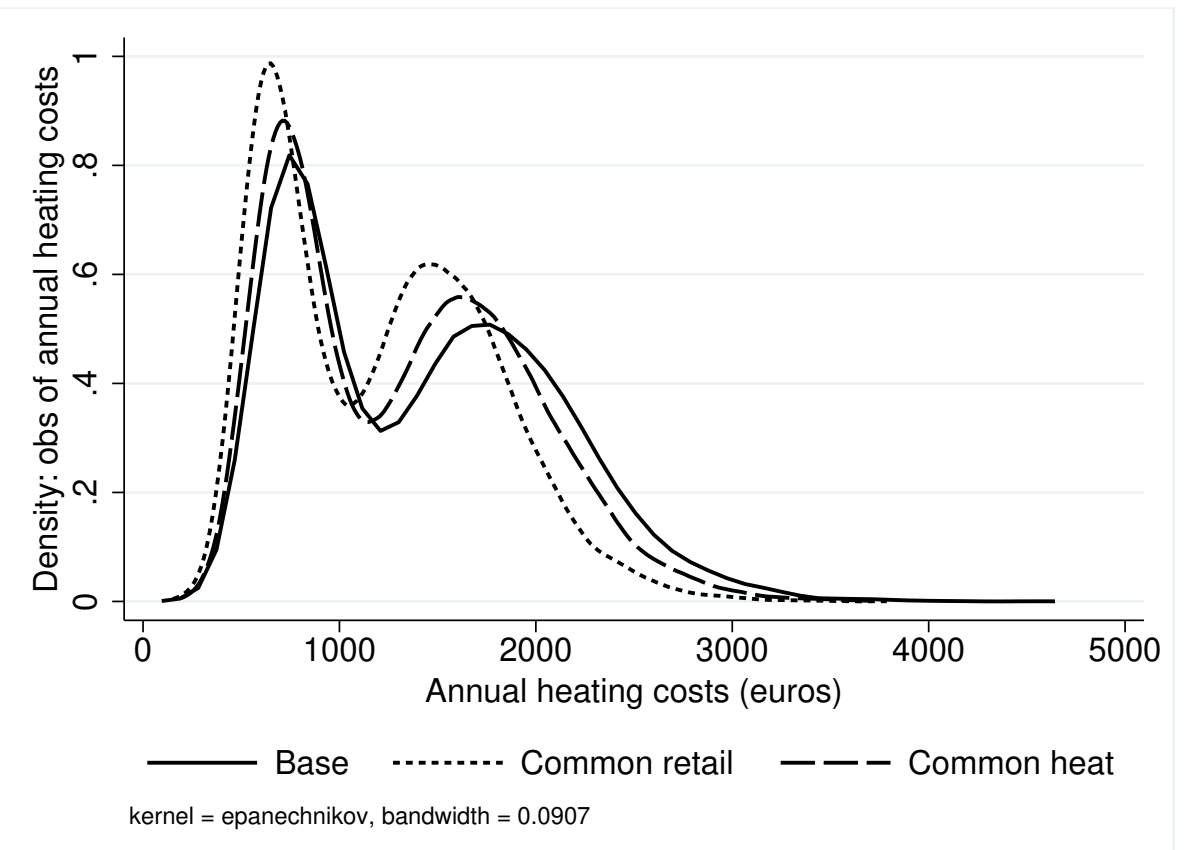

Figure D.1: Distribution of annual heating costs in the estimation sample at alternative definitions of costs.

Notes: The figure shows the distribution of annual heating costs in the estimation sample for alternative ways of defining the electricity prices and energy consumption. "Base" refers to costs based on local distribution prices, local default retail prices and heat consumption that varies with local climate. "Common retail" refers to costs where local default retail prices are replaced by the lowest retail price available nationwide. The retail price does not vary across observations. "Common heat" refers to costs where the heat consumption is set equal to $100 \mathrm{kWh}$ per square meter for all locations.

Source: Author's calculations.

Table D.1: Comparison of heating system purchase costs.

\begin{tabular}{lccc}
\hline & Average & Min & Max \\
\hline Electric heating & & & \\
Estimated costs & 5000 & 1481 & 10778 \\
Catalogue costs & 4288 & 1408 & 8822 \\
& & & \\
Hydroelectric heating & & & \\
Estimated costs & 9227 & 4160 & 16696 \\
Catalogue costs & 4585 & 2006 & 8360 \\
& & & \\
Ground heat & & & \\
Estimated costs & 17657 & 10602 & 24830 \\
Catalogue costs & 16899 & 16138 & 17827 \\
\hline \hline
\end{tabular}

Notes: The table presents summary statistics on heating system purchase costs by installed heating system in the estimation sample. Costs are constructed for the houses in the sample using two alternative sources of information: a survey with reported heating system purchase costs (estimated costs) and a catalogue of prices for all materials and labour required when building a house (catalogue costs).

Source: Author's calculations based on survey data provided by RTS Ltd. and the catalogue of costs published by the Building Information Foundation. 


\section{Appendix E Additional results}

\section{E.1 Heating system choice and annual heating costs}

This section presents results from a conditional logit estimation of heating choice using annual heating costs only. I estimate the following equation on the same sample as the WTP estimations:

$$
u_{i j}=\left(\bar{\gamma}+\sum_{k} \gamma_{k} z_{i k}\right) C_{i j}+A_{j}+\kappa_{i j}
$$

This equation is identical to the WTP estimation, but it omits the heating system purchase cost: included are the expected annual heating cost $C_{i j}$, interactions of this variable with household characteristics $z_{i k}$ and a constant for electric heating $A_{j}$. Table E.1 presents the coefficients and average marginal effects from the estimation. A more detailed discussion of the heterogeneity in marginal effects can be found in section 5.3 in the main text.

\section{E.2 Estimation on survey data}

The survey data provide additional information, as they allow using reported heating system purchase cost for the chosen option in the WTP estimation. This section reports estimation results on the survey data, using both the constructed costs and reported costs. Note that in both cases the costs for the non-chosen option need to be constructed. The survey contains no additional information on expected heating costs and therefore these are formed in the same way as for the register data.

To make the sample comparable to the estimation sample of the register data, the sample is restricted to include only electric heating, hydroelectric heating and ground heat. Because the survey is not as detailed in household characteristics as the registry data, the specifications are not identical. The estimation includes family size, an indicator for high income (annual gross household income higher than $€ 80000$ ) and an indicator for location in a town plan area as interactions with the heating cost variable. As in the register data estimation, municipality indicators are includes as well as an alternative specific constant for electric heating.

Table E. 2 reports the results. Specification 1 is based on the reported heating costs. This produces a very high value for the WTP, the median in the estimation sample being 53. At a 1 percent discount rate, this value is consistent with a lifetime of around 75 years. This implies that households are extremely forward-looking, perhaps too much so for this to be a reliable estimate. Specification 2 is based on constructed heating system costs. This estimation results in a WTP which is much closer to the value obtained from the register data; the median in the estimation sample is 11 . This result is consistent with a lifetime of 15 years and discounting at 1 percent.

In both specifications, the impact of income and location have the same sign as in estimations on register data: higher income indicates a higher WTP and a town location indicates lower WTP. The effect of family size is very imprecisely estimated.

Estimation on the survey data produces higher WTP values even when costs are constructed in the same way as for the register data. This indicates that there may be a sample selection issue with the survey data. The very high WTP estimate obtained with the reported costs is likely to be due to the very high variance in the reported heating system costs and the small amount of observations. It seems likely that the survey respondents have included different things in their measures of "approximate total heating 
Table E.1: Annual heating costs and heating technology choice

\begin{tabular}{lcc}
\hline & 1 & 2 \\
\hline Annual heating cost & -0.073 & -0.144 \\
& $(0.084)$ & $(0.102)$
\end{tabular}

Interactions with annual heating costs

\begin{tabular}{|c|c|c|}
\hline Town plan area & $\begin{array}{c}0.040 \\
(0.003)\end{array}$ & $\begin{array}{c}0.044 \\
(0.004)\end{array}$ \\
\hline Year 2011 & $\begin{array}{l}-0.030 \\
(0.003)\end{array}$ & $\begin{array}{l}-0.028 \\
(0.003)\end{array}$ \\
\hline Household net income & & $\begin{array}{l}-0.001 \\
(0.000)\end{array}$ \\
\hline Household debt & & $\begin{array}{c}0.003 \\
(0.000)\end{array}$ \\
\hline Age & & $\begin{array}{c}0.001 \\
(0.000)\end{array}$ \\
\hline Undergraduate & & $\begin{array}{l}-0.018 \\
(0.004)\end{array}$ \\
\hline Graduate & & $\begin{array}{l}-0.029 \\
(0.005)\end{array}$ \\
\hline Children & & $\begin{array}{l}-0.013 \\
(0.006)\end{array}$ \\
\hline Family size & & $\begin{array}{c}0.001 \\
(0.002)\end{array}$ \\
\hline House owner & & $\begin{array}{c}0.026 \\
(0.004)\end{array}$ \\
\hline Experience & & $\begin{array}{c}0.024 \\
(0.007)\end{array}$ \\
\hline Material: stone & & $\begin{array}{l}-0.052 \\
(0.006)\end{array}$ \\
\hline constant: electric heating & & $\begin{array}{c}0.779 \\
(0.033)\end{array}$ \\
\hline No. of households & 11418 & 8891 \\
\hline $11 \_0$ & $-1.25 \mathrm{e}+04$ & -9767.762 \\
\hline 11 & $-1.17 \mathrm{e}+04$ & -8373.903 \\
\hline
\end{tabular}

\begin{tabular}{lcc} 
Average marginal effect & & \\
& -0.005 & -0.010 \\
& $(0.000)$ & $(0.000)$ \\
\hline \hline
\end{tabular}

Notes: The table presents coefficients from a conditional logit estimation of heating system choice on annual heating costs. The options are electric heating, hydroelectric heating and ground heat.

Source: Author's calculations. 
Table E.2: Heating choice estimation, survey data

\begin{tabular}{lcc}
\hline & 1 & 2 \\
\hline Purchase cost & -0.035 & -0.308 \\
& $(0.020)$ & $(0.033)$ \\
Heating cost & -2.464 & -3.198 \\
& $(0.584)$ & $(0.415)$
\end{tabular}

Interactions with heating cost

\begin{tabular}{lcc} 
Gross income $>80000$ & -0.540 & -0.679 \\
& $(0.183)$ & $(0.129)$ \\
Family size & -0.038 & 0.003 \\
& $(0.053)$ & $(0.039)$ \\
Town plan area & 0.455 & 0.173 \\
& $(0.180)$ & $(0.126)$ \\
\hline Observations & 3387 & 5889 \\
Log likelihood & -679 & -1502 \\
No. of households & 1129 & 1963 \\
\hline WTP in estimation sample & \\
Median & 53 & 11 \\
\hline \hline
\end{tabular}

Notes: The table presents results from a conditional logit estimation of heating system choice. The options are electric heating, hydroelectric heating and ground heat. All specifications include a constant for electric heating and municipality indicators interacted with the annual heating cost. Column 1 reports results based on stated heating system costs, column 2 reports results based on constructed heating system costs. Source: Author's calculations.

costs", as it is not possible that ground heat would have been installed at a cost of less than $€ 1000$ (the minimum reported cost for ground heat in the survey is $€ 500$ ). 